\title{
The Jump Dynamics of the Industry-Specific Nominal Effective Exchange Rate of RMB and the Impact of Major International Currencies on It-An Empirical Study Based on the ARJI Model
}

\author{
Yuqi Wang \\ Institute of Industrial Economics, Jinan University, Guangzhou, China \\ Email:wyqelisa@163.com
}

How to cite this paper: Wang, Y. Q. (2018). The Jump Dynamics of the Industry-Specific Nominal Effective Exchange Rate of RMB and the Impact of Major International Currencies on It-An Empirical Study Based on the ARJI Model. Journal of Financial Risk Management, 7, 65-98.

https://doi.org/10.4236/jfrm.2018.71005

Received: March 1, 2018

Accepted: March 25, 2018

Published: March 28, 2018

Copyright $\odot 2018$ by author and Scientific Research Publishing Inc. This work is licensed under the Creative Commons Attribution International License (CC BY 4.0).

http://creativecommons.org/licenses/by/4.0/

\section{(c) (i) Open Access}

\begin{abstract}
In this paper, the Autoregressive Jump Intensity (ARJI) model with time-varying jumps is used to measure the daily exchange rate volatility and jump intensity of 13 Chinese manufacturing segments from January 1, 2001 to June 30,2017 . The statistical characteristics are analyzed and compared. We further explore the impact of international major payment currencies' volatility on the industry-specific nominal effective exchange rate (INEER) risks for various industries in China. First, the results show that there are certain differences in exchange rate fluctuation and jump dynamics between different industries. The exchange rate volatility and jump intensity for paper, non-metal and metal industries are small, while for petroleum, rubber, electrical machinery and other industries are larger. Second, the U.S. dollar, German mark and Japanese yen have significantly different effects on exchange rate fluctuations and jump risks in various industries, and the degree of impact is weakened in turn. Finally, the analysis of the sub-sample shows that after the financial crisis, the impact of dollar and yen on the fluctuations of INEER for most industries has declined significantly, and the impact of mark has generally increased.
\end{abstract}

\section{Keywords}

Exchange Rate Risks, INEER Returns, GARCH, Jump Intensity

\section{Introduction}

Since the collapse of the Bretton Woods agreement in the 1970s, especially since 
1976 when Jamaica Accord formally recognized the legitimacy of floating exchange rate regimes, exchange rate volatility has gradually entered the field of public vision as an important source of macroeconomic uncertainty and has become the subject of research conducted by many scholars (Jorion, 1988; Bayoumi \& Eichengreen, 1998; Devereux \& Engel, 2002; Giannellis \& Papadopoulos, 2011).

On the one hand, with the deepening of economic globalization, international trade has become more frequent and the degree of liberalization of capital flows has gradually increased. As the main international payment currencies, the price ratio between the U.S. dollar, the German mark and the Japanese yen has been drastically rising and falling. And the frequencies of large exchange rate fluctuations which are difficult to be explained by general exchange rate decision models appear to be higher and higher. Compared to continuous exchange rate fluctuations, abnormal exchange rate jumps are harder to capture and their impact on the economy is more sustained and deeper. Taking the Asian financial crisis that erupted in the second half of 1997 as an example, the exchange rates of Thai Baht, Philippine Peso, Malaysian Jitel, Indonesian Rupiah and Singapore dollar dropped sharply during this period, and the worst-hit Thai Baht exchange rates fell nearly $40 \%$. The turmoil in the foreign exchange market also brought a plunge in the stock market. Hong Kong Hang Seng Index, for example, dropped from a peak of 16,820 points in August 1997 to a bottom of 6,544 points in $\mathrm{Au}$ gust 1998. The decline process has continued for one year and the market suffered a drop of $61.1 \%$. The crisis has brought huge wealth losses to investors. Therefore, as an important source of non-diversifiable risk in the foreign exchange market, exchange rate jump risk is not only important to the enterprises engaged in foreign trade business, but also vital for investors in the foreign exchange market and policy makers who must make decisions in real time during times of jump-inducing chaotic conditions in financial markets (Li, $\mathrm{Zhu}, \& \mathrm{Li}$, 2016).

On the other hand, as a large open country with a high degree of dependence on international trade, our economy has continuously deepened its economic ties with foreign countries. Frequent multilateral economic exchanges have drawn more and more attention on the fluctuations of the effective exchange rate. The effective exchange rate is the trade-weighted-average of the bilateral exchange rates of one currency against the other currencies. Compared with a single bilateral exchange rate, this indicator can comprehensively reflect the actual purchasing power and overall competitiveness of a country's currency in international trade. However, the early studies on effective exchange rate in our country mainly focus on the national aggregate level (Zou et al., 2016). There are few studies at the industry level. In recent years, the "Going out" strategy and the "Belt and Road Initiative" have promoted the internationalization of China's industry development. The strategy of industrial transformation and upgrading inevitably leads to the differentiation of development levels of different industries. Accompanied with this, the exchange rate risks faced by various industries 
are constantly increasing and differentiated according to the depth of participation in internationalization. For example, the food industry and the oil industry have different international supply and demand and under different competitions, which means the pattern of their foreign exchange risks could not be generalized. This puts forward higher requirements on the analysis and management of exchange rate risks of different industries.

In academia, first of all, the basic models used in a large number of articles on exchange rate risk that measure exchange rate volatility fall into three categories: the historic volatility models based on sample standard deviation; the stochastic volatility (SV) models; and the generalized autoregressive conditional heteroskedasticity (GARCH) model. The basic form of the three types of models can not capture or separate jump risks from exchange rate volatility. Therefore, although many scholars have used the three basic models to explore the characteristics and sources of exchange rate fluctuations, there are still few articles on the determinants of foreign exchange rate jump risk. Second, the existing literature seldom deals with the analysis of exchange rate risk at industry level. In our country, only in recent years have scholars started to compile industry-specific exchange rates according to different standards and studied its determinants (Chen, Wan, \& Fu, 2010; Xu \& Tian, 2013; Zou, You, \& Fu, 2016). However, to the best of my knowledge, there is no literature trying to capture the large and non-diversifiable jump risk in industrial exchange rate fluctuations and explore its determinants. And this, consequently, lead to the lack of theoretical and data support for the management of jump risk in industrial exchange rate volatility. This article is about to make efforts in this area.

Due to the importance of the aforementioned two problems and the lack of empirical research, this paper applies the Autoregressive Jump Intensity (ARJI) model proposed by Chan \& Maheu (2002) to daily industry-specific nominal effective exchange rate (INEER) of 13 Chinese industries from January 1, 2001 to June 30, 2017 and estimates their time-varying conditional volatility and jump intensity. The exchange rate jump dynamics are analyzed and compared among different industries. And the impact of the main international payment currencies on the exchange rate volatility and jump risk of various industries is further explored.

The paper proceeds as follows. The nest section is a literature review, which illustrates the domestic and foreign research on the jump intensity of the returns and the research on the industry-specific exchange rate risk; Section 3 outlines the empirical methods and data used in this paper; Section 4 presents the empirical results; Section 5 conducts robustness check; main conclusions, contributions, deficiencies and future research prospects then follow in Section 6.

\section{Literature Review}

The literature review is divided into two parts. The first part is a comprehensive review of the research on the volatility of returns with jump constituents, which paves the way for the introduction of ARJI model. The second part mainly re- 
views the research status and achievements about the industry-specific effective exchange rate.

\subsection{Research on the Volatility of Returns with Jump Components}

The time series such as exchange rate, interest rate and stock return generally have non-normal distribution. That is: the probability values near the tail and the average of their distribution are larger than the normal distribution, while the probability of the rest is smaller than that of the normal distribution, which can be called "leptokurtosis and fat-tail"; large fluctuations followed by large fluctuations and small fluctuations followed by small fluctuations, which can be called "volatility clustering". In the study of return volatility, the traditional heteroscedasticity variance or the evolving heteroscedasticity model is apparently invalid for this special heteroscedasticity of market returns. To solve this problem, Engle (1982) propose the autoregressive conditional heteroscedasticity (ARCH) model, which assumes that the current variance depends on the previous residuals, reflecting the current variance is related to the volatility of the previous period. The factual evidence proves that the model considering variance volatility is more effective in predicting the variance. However, in the $\mathrm{ARCH}(\mathrm{p})$ model, once $\mathrm{p}$ is large, there will be too many parameters to be estimated, resulting in loss of sample capacity. As an optimization, Bollerslev (1986) propose a generalized autoregressive conditional heteroscedasticity (GARCH) model. In GARCH model, the variance term depends on the lag variance and the lag (squared) residual, and the persistence of the volatility can be captured with relatively few parameters, which makes the prediction of the future conditional variance more accurately.

Then there are many scholars try to expand the ARCH and GARCH models, which can be summarized into three main directions. First is the further expansion of the model application-Engle, Lilien, \& Robins (1987) put forward the ARCH-M model to explore the relationship between the excess return rate of financial assets and risk premium; Second is the asymmetric research-Glosten, Jagannathan, \& Runkle (1993) explore the differences in the effects of "good news" and "bad news" on asset price volatility. They find that the volatility caused by "bad news" was significantly greater than that caused by "good news", and then they put forward the asymmetric "Threshold GARCH" (TARCH) model; Third is the introduction of Poisson jump terms-Chan \& Maheu (2002) propose the ARJI model to study the jump dynamics of stock market returns. Jump in the market is an important source of non-diversifiable risk (Bollerslev et al., 2008; Eraker et al., 2003), and the impact of jump risk is more profound and lasting than the smooth fluctuation, which is the focus of risk management. Therefore, the introduction of jump in the GARCH model is the main expansion that we focus on.

An early exploration of the jump model originated from the study conducted by Press (1967). For the first time, he introduces the basic Poisson jump model of stock returns into the financial field and proposed a composite event model. 
The model assumes that the number of events that cause price changes follows the Poisson distribution. The jump size is random and subject to the normal distribution. This model has a good fit for the skewness and excess kurtosis of asset returns. Subsequently, scholars such as Akgiray \& Booth (1988), Tucker \& Pond (1988), and Hsieh (1989) find that a normal-Poisson jump model matches the statistical characteristics of daily exchange rate pretty well. Ball \& Torous (1983) apply this model to stock returns and get similar conclusions. These empirical studies have proven the validity of Press model.

Given its good empirical performance, the basic jump model has been developed in many ways. Some scholars (Jorion, 1988; Vlaar \& Palm, 1993; Wolff, Nieuwland, \& Verschchoor, 1994) try to combine the jump setting with the ARCH/GARCH model to get a GARCH-JUMP model in which GARCH explains the continuous changes in asset returns, While JUMP explains the large and discrete changes in asset returns.

Subsequent empirical studies (Bates, 1991; Chan \& Maheu, 2002) show that the probability of jumps is highly likely to change over time. Thus the assumption of constant Poisson distributions is a common defect of all these GARCH-JUMP models. On condition of that, many scholars devoted themselves to introducing the time-varying jump distribution into the GARCH-JUMP model. Das (1998) and Fortune (1999), for example, introduce changes in weekly jump intensity by using dummy variables. Chernov et al. (1999) estimate specifications that allow the jump intensity to change with previous jump and random fluctuations. Chan \& Maheu (2002) propose a new conditional jump model (ARJI) to study the jump dynamics of stock market returns. This model allows conditional jump densities to change over time and asymptotically follows an autoregressive moving average (ARMA) process. They find that both the conditional jump intensity and the distributions of jump size have significant time-varying characteristics. Further studies showed that this condition jump dynamics is good for the fitting and prediction of stock market volatility. Subsequently, based on the model of Chan \& Maheu (2002), Maheu \& McCurdy (2004) further include historical jumping factors into the GARCH volatility equation. And by taking into account the impact of the current jump and the historical jump on the total volatility, they establish the GARJI model, which has been used to study individual stock returns and market composite index in the U.S. They find that compared with the historical jump, the current jump has a more significant asymmetric impact on the volatility.

At present, although few research have been conducted on the jump dynamics of returns volatility in China, there are still some scholars who have made important contributions. Such as Yang \& Chen (2001), they propose the index option model based on the jump process. By introducing jump in the description of the movement of the stock price, they put forward the pricing equation and pricing model of index options under certain conditions, which can effectively avoid the theoretical inconsistency by using diffusion process to describe the movements of price index and the price changes of individual stocks. Tong \& 
Liu (2006) apply the GARCH-JUMP model to the returns of A shares and B shares in Shanghai and Shenzhen Stock Exchange and find that this model can effectively estimate the jump changes of the returns and volatility. Applying the GARCH-JUMP model to daily returns of the ten largest international securitized real estate markets, Li et al. (2015) find that large price jumps exist during both crisis and non-crisis periods in major international securitized real estate markets. They further investigated the sources of large price changes and find that jump intensity is inversely related to the degree of economic and financial integration. Li, Zhu, \& Li (2016) applied the ARJI model to weekly bilateral exchange rate returns of 31 countries over the period 2001-2013 and examine the determinants of bilateral exchange rate risks. Their empirical results show that bilateral exchange rate risks can be significantly reduced by external financial liabilities and the development of domestic financial sectors will attenuate this effect.

It can be seen from the above literature that the GARCH model and the jump model have their own advantages in capturing the special fluctuations and non-normal distributions of returns, and they gradually merge into the GARCH-JUMP model, which include the Constant-GARCH, Models, ARJI models and other variants. These models are widely used to study fluctuations and jump dynamics in stock market and foreign exchange market. Jorion (1988) has pointed out that the jump characteristics of foreign exchange market is more obvious than the stock market. Taking into account the importance of foreign exchange risk research in today's global economy, this article will use the ARJI model with time-varying jumps to explore the volatility and jump intensity of the daily industry-specific nominal RMB exchange rate.

\subsection{Research on Industry-Specific Effective Exchange Rates}

Foreign scholars' research on industry-specific effective exchange rate started with the article by Goldberg (2004). When studying the depreciation of the trade-weighted U.S. dollar, Goldberg proposes that compared with aggregate trade-weighted exchange rates, industry-specific indexes is more effective in capturing changes in industry competitive conditions induced by moves in specific bilateral exchange rates. Fazio et al. (2007) use the industry exchange rate data to study the heterogeneity effect in the deviation of product price from the law of one price. Sato, Shimizu, Shrestha, \& Zhang (2013) construct the industry-specific effective exchange rates of RMB, JPY and KRW. They point out that there are significant differences in real effective exchange rate (REER) among different industries in different countries. Sato et al. (2015) construct monthly industry-specific effective exchange rate based on the producer price indices of nine Asian economies from 2001 to 2014. Their empirical research shows that the weighted average real effective exchange rate is more effective in reflecting export competitiveness than the REER announced by the Bank for International Settlements (BIS).

In China, during early period, the research on effective exchange rate mostly 
focused on the national level (Zou et al., 2016). Only in recent years have scholars started to compile industry-specific exchange rates according to different standards and studied its determinants. For example, Chen, Wan, \& Fu (2010) calculate the industry-specific nominal effective exchange rate of 11 industries in China based on the proportion of China's exports to the 14 main trading partners. Then they analyze the impact of industry-specific indexes on the competitiveness of industrial export prices and come to the conclusion that the impact is different by industry whether in short-term or in long-term. Xu \& Tian (2013) point out that there are significant differences in the real effective exchange rates of different industries in China and the REER at the national level, as measured by the traditional method, has neglected the heterogeneity among different industries. Thus they measure the REER at industry-level in China from 2000 to 2009, and through further empirical study, they find that industry-specific indexes is significantly better than the aggregate indexes in revealing the relationship between trade and exchange rate. In order to accurately estimate the impact of major international currencies on the competitiveness of different industries, Zou, You, \& Fu (2016) construct industry-specific nominal effective exchange rate of eight manufacturing subdivision industries based on bilateral exchange rate of RMB and bilateral trade flows between China and its major trading partners. By comparison, they find that although the nominal exchange rate (NEER) of various industries share same trend in the long run, the relative value and degree of volatility varies by industry. Their further research demonstrate that the impact of the U.S. dollar, euro and Japanese yen on the industry-specific nominal effective exchange rate decreases in turn and that the U.S. dollar plays a decisive role in the export competitiveness of various industries in China.

Based on the domestic and foreign research on the effective exchange rate of different industries, we could draw the conclusion that the industry-specific effective exchange rate is more effective in reflecting the international competitiveness of different industries than the aggregate indexes. Therefore, this paper focuses on the fluctuation of industry-specific nominal effective exchange rate (INEER). We will compare the volatility and jump dynamics of different industries' INEER, and more importantly, further study the different impact of main international payment currency on INEER fluctuations of different industries.

\section{Empirical Models, Variables and Data}

Frankel \& Wei (1994) first determined the peg of the exchange rate against the major currencies by examining the effect of major international currencies on the exchange rate of an economy. This paper uses the Frankel-Wei model to study the impact of the U.S. dollar, German mark and Japanese yen on China's INEER of 13 industries. The basic empirical model is as follows:

$$
V O L / J U M P=f\left(V O L \_U S D, V O L \_D E M, V O L \_J P Y\right)
$$


where exchange rate volatility ( VOL)/jump intensity (JUMP) of various industries is a function of the exchange rate volatility of the U.S. dollar, German mark and Japanese yen (VOL_USD,VOL_DEM,VOL_JPY ).

\subsection{Time-Varying Conditional Volatility and Jump Intensity}

In this section, I use the ARJI model proposed by Chan \& Maheu (2002) to estimate the time-varying conditional volatility and jump intensity of the INEER of China's 13 manufacturing segments from January 1, 2001 to June 30, 2017.

\subsubsection{Basic Equation}

Define the information set at time $\mathrm{t}$ to be the history of returns: $\Phi_{t}=\left\{R_{t}, \cdots, R_{1}\right\}$, where $R_{t}$ is the first difference of nominal exchange rate in the logarithmic form.

Assuming that the exchange rate return is made up of three parts, the first part is the ARMA process of the conditional means; the second part is the conditional GARCH volatility; and the third part is the conditional jump. Then the model combines the jump specification with a GARCH parameterization of volatility and is specified as:

$$
R_{t}=\mu+\phi_{1} R_{t-1}+\phi_{2} R_{t-2}+\sqrt{h_{t}} z_{t}+\sum_{k=1}^{n_{t}} Y_{t, k}
$$

where $z_{t} \sim \operatorname{NID}(0,1)$ is the information impact of GARCH variance, which is considered as an independent standard random variable. Given $\Phi_{t}$, the jump size $Y_{t, k}$ is postulated to be independently drown from a normal distribution with time-varying mean $Y_{t, k}$ and constant variance $\delta_{t}^{2}$, and $z_{t}$ is also specified as an independent normal random variable.

\subsubsection{The GARCH Variance}

Assuming that $h_{t}$ follows a GARCH $(1,1)$ process for a given $\Phi_{t}$ :

$$
h_{t}=\omega+\alpha_{1} \varepsilon_{t-1}^{2}+\beta_{1} h_{t-1}
$$

where $\varepsilon_{t}=R_{t}-\mu-\phi_{1} R_{t-1}-\phi_{2} R_{t-2}$. The specification of $\varepsilon_{t}$ allows past shocks to affect expected volatility, and captures the smooth autoregressive changes in the conditional variance that are predictable based on the information set $\Phi_{t-1}$.

\subsubsection{The Number of Jumps}

Let $n_{t}$ denotes the number of jumps that arrive between $t-1$ and $t$, who is assumed to follow the Poisson distribution and $\lambda_{t}\left(\lambda_{t}>0\right)$ is the parameter. The density function is as follows:

$$
P\left(n_{t}=j \mid \Phi_{t-1}\right)=\frac{\exp \left(-\lambda_{t}\right) \lambda_{t}^{j}}{j !}, j=0,1,2, \cdots
$$

As we know, $\lambda_{t}$ is the mean and variance of the Poisson distribution, which is called the jump intensity in the previous study. The Constant-GARCH model treats it as a fixed value. ARJI models such as ARJI- $R_{t-1}^{2}$ and ARJI- $h_{t}$ allow it to change over time. 


\subsubsection{The Jump Intensity}

The conditional jump intensity $\lambda_{t}$ is the expectation of the number of jumps for a given $\Phi_{t-1}$, namely $\lambda_{t}=E\left[n_{t} \mid \Phi_{t-1}\right]$. The ARJI model proposed by Chan \& Maheu (2002) allows $\lambda_{t}$ to endogenously evolve according to a parsimonious ARMA structure. The dynamics directing $\lambda_{t}$ is parameterized as:

$$
\lambda_{t}=\lambda_{0}+\rho \lambda_{t-1}+\gamma \xi_{t-1}
$$

where

$$
\xi_{t-1}=E\left[n_{t-1} \mid \Phi_{t-1}\right]-\lambda_{t-1}=\sum_{j=0}^{\infty} j P\left(n_{t-1}=j \mid \Phi_{t-1}\right)-\lambda_{t-1}
$$

Equation (5) states that the conditional jump intensity for period $t$ depends on the conditional jump intensity for period $t-1$ and the first-order lag value of $\xi_{t}$, which is the difference between the prediction and the real value of $n_{t-1}$. And $P\left(n_{t-1}=j \mid \Phi_{t-1}\right)$ from Equation (6) is called the filter and is an ex post inference on $n_{t-1}$ given $\Phi_{t-1}$. According to Bayes rule, the filter is as follows:

$$
P\left(n_{t}=j \mid \Phi_{t}\right)=\frac{f\left(R_{t} \mid n_{t}=j, \Phi_{t-1}\right) P\left(n_{t}=j \mid \Phi_{t-1}\right)}{P\left(R_{t} \mid \Phi_{t-1}\right)}, j=0,1,2, \cdots
$$

According to the total probability formula, there are:

$$
P\left(R_{t} \mid \Phi_{t-1}\right)=\sum_{j=0}^{\infty} f\left(R_{t} \mid n_{t}=j, \Phi_{t-1}\right) P\left(n_{t}=j \mid \Phi_{t-1}\right)
$$

Recalling the assumptions of Equation (2), the implied message is:

$$
f\left(R_{t} \mid n_{t}=j, \Phi_{t-1}\right)=\frac{1}{\sqrt{2 \pi\left(h_{t}+j \delta^{2}\right)}} \times \exp \left(-\frac{\left(R_{t}-\mu-\sum_{i=1}^{l} \phi_{i} R_{t-i}-\theta j\right)^{2}}{2\left(h_{t}+j \delta^{2}\right)}\right)
$$

With Equations (7)-(9), the parameters in Equation (5) and Equation (6) can be estimated.

\subsubsection{The Jump Size}

Different specifications of jump size distribution result in different versions of the ARJI model: basic-ARJI model, ARJI- $R_{t-1}^{2}$ model and ARJI- $h_{t}$ model. The basic-ARJI model assumes that the conditional mean and conditional variance of the jump size are both constant, namely $\theta_{t}=\theta, \delta_{t}^{2}=\delta^{2}$. However, the distribution of jump size can also change over time. In the literature, the basic-ARJI model has two extensions.

The first extension is ARJI- $R_{t-1}^{2}$ model, which allows the conditional mean and conditional variance of the jump size to be conditionally normal and a function of past returns. The mean and variance equations are as follows:

$$
\begin{gathered}
\theta_{t}=\eta_{0}+\eta_{1} R_{t-1} D\left(R_{t-1}\right)+\eta_{2} R_{t-1}\left(1-D\left(R_{t-1}\right)\right) \\
\delta_{t}^{2}=\zeta_{0}^{2}+\zeta_{1} R_{t-1}^{2}
\end{gathered}
$$

The second extension is ARJI- $h_{t}$ model, which allows $h_{t}$ instead of $R_{t-1}^{2}$ to affect the variance. The equation of conditional mean and variance is as follows: 


$$
\begin{gathered}
\theta_{t}=\eta_{0}+\eta_{1} R_{t-1} D\left(R_{t-1}\right)+\eta_{2} R_{t-1}\left(1-D\left(R_{t-1}\right)\right) \\
\delta_{t}^{2}=\zeta_{0}^{2}+\zeta_{1} h_{t}
\end{gathered}
$$

where $D(x)=1$ if $x>0$ and 0 otherwise, and $\eta_{0}, \eta_{1}, \eta_{2}, \zeta_{0}$ and $\zeta_{1}$ are parameters to be estimated.

\subsubsection{The Conditional Jump Variance and the Total Conditional Variance}

According to Chan \& Maheu (2002), the conditional jump variance for returns is:

$$
\operatorname{var}\left[C_{t} \mid \Phi_{t-1}\right]=\left(\delta_{t}^{2}+\theta_{t}^{2}\right) \lambda_{t}
$$

And the total conditional variance (total exchange rate volatility) is:

$$
\operatorname{var}\left(R_{t} \mid \Phi_{t-1}\right)=h_{t}+\left(\delta_{t}^{2}+\theta_{t}^{2}\right) \lambda_{t}
$$

For the basic-ARJI model, we replace $\delta_{t}^{2}$ and $\theta_{t}^{2}$ with $\delta^{2}$ and $\theta^{2}$.

\subsection{Exchange Rate Volatility of Major International Currencies}

The SDR currency basket consists of the U.S. dollar, euro, Chinese yuan, Japanese yen and German mark. Except for Chinese yuan, the three currencies with the largest weights are U.S. dollar, euro and Japanese yen. According to the data released by Federal Statistical Office of Germany (FSO), China replaced the United States in 2016 and for the first time became Germany's largest trading partner. Therefore, I choose the U.S. dollar, the German mark and the Japanese yen to study their impact on China's industry-specific exchange rate fluctuations. The GARCH model proposed by Bollerslev (1986) can better catch the "volatility clusters" characteristics of returns and is more accurate than the ARCH model. Therefore, I use the simple GARCH $(1,1)$ model to calculate the daily volatility of dollar, mark and yen. Taking dollar for example, the estimation model is as follows:

$$
V O L \_U S D_{t}=\omega+\alpha_{1} \varepsilon_{t-1}^{2}+\beta_{1} V O L \_U S D_{t-1}
$$

where VOL_USD $D_{t}$ is the variance of the dollar exchange rate return, that is, exchange rate volatility. The generation of disturbance term $\varepsilon_{t}$ is:

$$
\varepsilon_{t}=v_{t} \sqrt{\omega+\alpha_{1} \varepsilon_{t-1}^{2}+\beta_{1} V O L \_U S D_{t-1}}
$$

where $v_{t}$ is a white noise process.

\subsection{Data}

The nominal effective exchange rate (NEER) is an unadjusted weighted average rate at which one country's currency exchanges for a basket of multiple foreign currencies, and its volatility effectively reflects the information impact on the foreign exchange market. Considering the availability of data, this paper uses the industry-specific nominal effective exchange rate (INEER) of 13 manufacturing sectors in China released by The Research Institute of Economics, Trade and 
Industry (RIETI), which is a policy think tank established in Japan in 2001 and undertakes public policy studies and analyses. RIETI database is based on the exchange rates and trade data of 29 countries from Asia, Europe, North America, Oceania and other areas in the world. It provides daily and monthly INEER of all 29 countries. Taking China as an example, the weight of INEER is the export share of the main manufacturing industries with the remaining 28 countries. Since the study conducted by Sato et al. (2015) demonstrates that the weighted average effective exchange rate is more effective in reflecting export competitiveness than the effective exchange rate announced by BIS, the daily NEER of dollar, mark and yen are also drawn from the RIETI database.

In view of the fact that the industry category of RIETI database contains the major manufacturing segments and could correspond well with ISIC and the Guidelines for Industry Classification of Listed Companies issued by China Securities Regulatory Commission (CSRC), the industry classification of this paper follows the industry category of RIETI database. The involved China's manufacturing segments include Food, Textile, Wood, Paper, Petroleum, Chemical, Rubber, Non-Metal, Metal, General Machinery, Electrical Machinery, Optical Instruments and Transport Equipment, for a total of 13. The descriptions of the industry classification and the correspondence with the major international and domestic classification standards are given in Table A1 in Appendix.

I take the logarithmic difference of the INEER to obtain the exchange rate return, and use the ARJI model to estimate the daily fluctuations and jump intensity of INEER. The monthly conditional volatility and jump intensity are measured as the average of the daily conditional volatility and the sum of the daily conditional jump intensity in each month respectively (The monthly GARCH variance of dollar, mark and yen is calculated by the same way). The time span of this study is from January 1, 2001 to June 30, 2017, with a total of 55,913 daily INEER data.

\section{Empirical Results}

\subsection{The Dynamics of INEER Volatility and Jump Intensity}

\subsubsection{The Statistical Analysis of INEER}

The basic statistics in Table A2 explain the difference between the value of INEER and the export competitiveness of various industries from January 1, 2001 to June 30, 2017. The paper industry has the lowest value of INEER mean, maximum and minimum, which implies that China's paper industry has strong export competitiveness. In contrast, both of the mean and maximum values of petroleum and chemical industry are high, reflecting that China's petroleum and chemical industry's export competitiveness is weak. What's more, the standard deviation of paper and wood industry is small, indicating that the export competitiveness of China's paper and wood industry is stable and not easily affected by fluctuations in the RMB exchange rate. However, the industry standard devia- 
tion of chemical and general machinery is large, indicating that the export competitiveness of these two industries is vulnerable to fluctuations in the exchange rate of RMB.

I further use the time series diagrams to analyze the distribution of China's 13 industries' nominal exchange rate fluctuations. Firstly, based on RIETI's INEER data, I plotted the time series diagrams of all 13 industries (Figure 1). It is easy to see that the overall trend of the INEER of various industries is the same, but the values of INEER at the same time and the range of change over time is significantly different among various industries. Thus, taking the food and textile industries as an example (other industries are in similar fashion), I draw out the time series diagrams of 13 industries' INEER, the logarithmic difference of INEER (returns), the absolute value of INEER returns, and the square of INEER returns to demonstrate the "leptokurtosis and fat-tail" and "volatility clustering" characteristics of INEER returns (Figure 2 \& Figure 3). According to this, I initially determine the GARCH model is suitable for the 13 industries' INEER series.

Next, I conduct normal test on INEER returns of these 13 industries. The results of both J-B test and K-S test show that the normal distribution hypothesis is rejected at the $1 \%$ significance level, which means it is not appropriate to capture the distribution features by the normal distribution model.

Finally, I verify the ARCH effect of the returns series. In this paper, I use the LM method to test the existence of conditional heteroskedasticity in the returns series of INEER. The results show that all the INEER returns series reject the null hypothesis that there is no ARCH effect at the 5\% significance level. Thus, I suppose that there is a significant ARCH effect (autoregressive effect) in the INEER returns sample of this paper. And since GARCH model can better

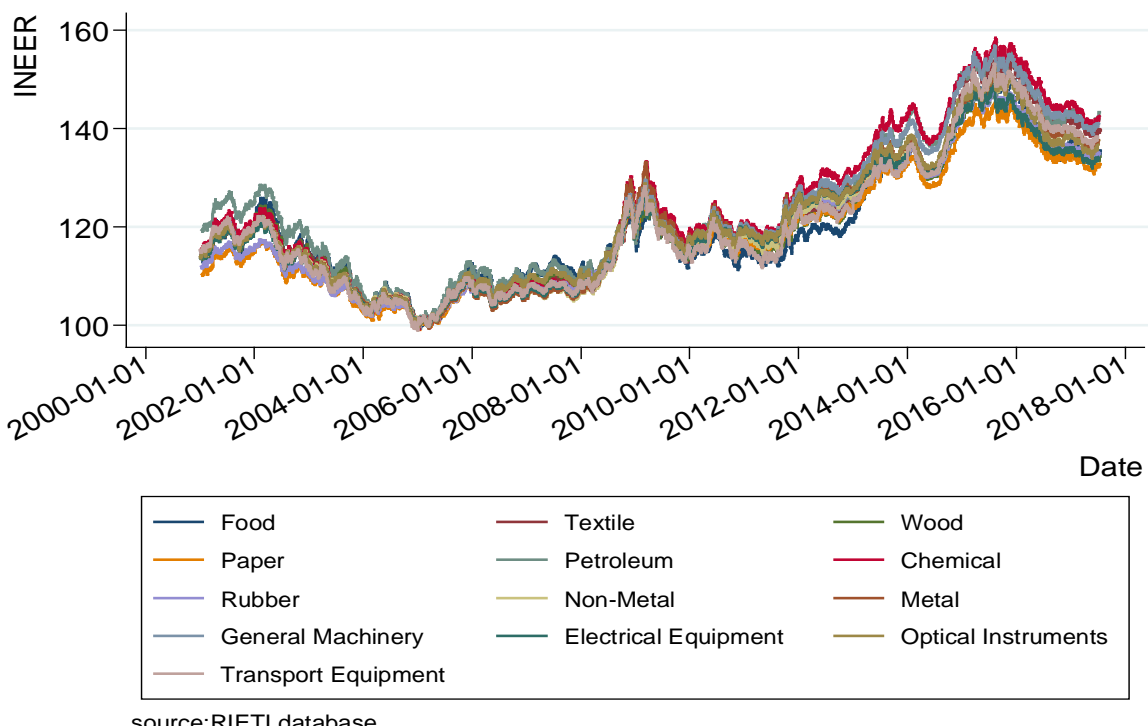

Figure 1. The time series graph of all industries' INEER. The sample period is from January 1,2001 to June 30, 2017. 


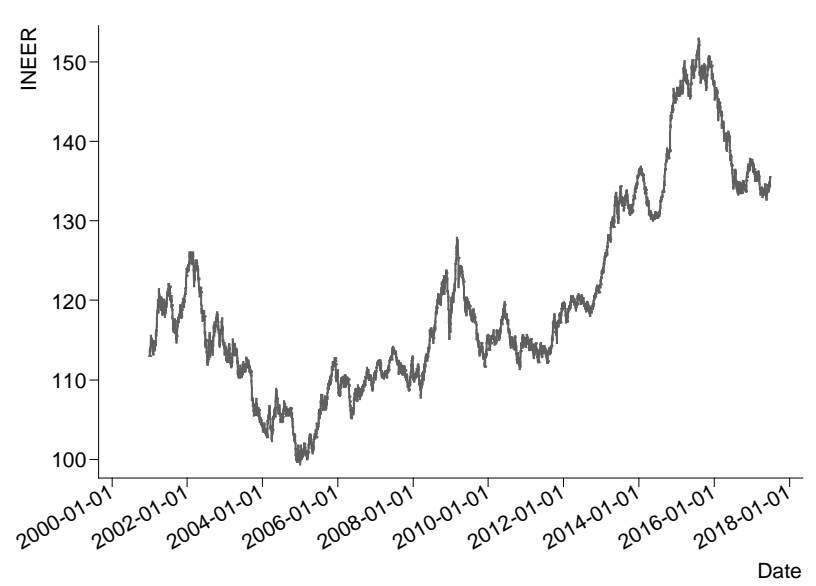

(a)

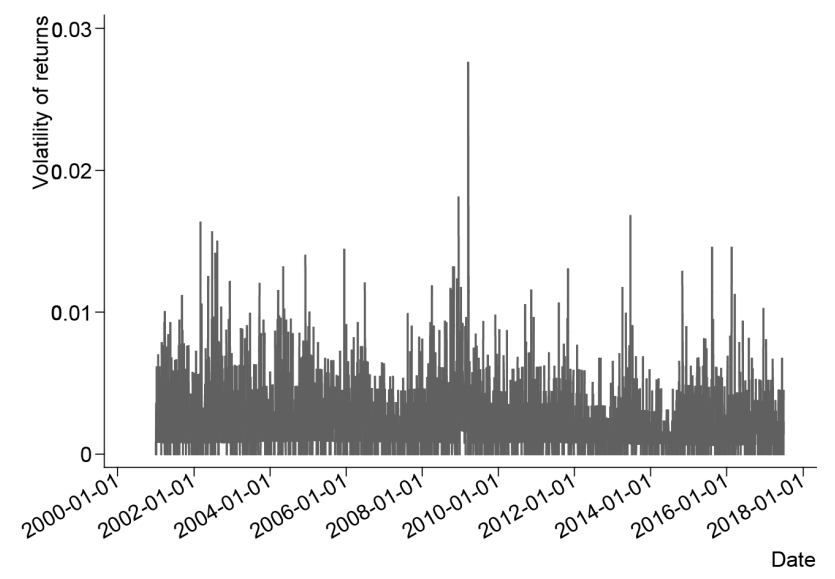

(c)

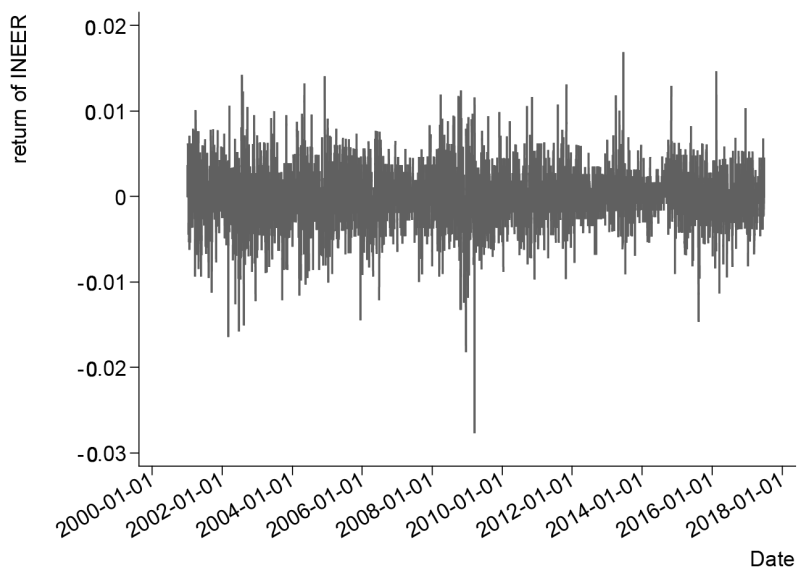

(b)

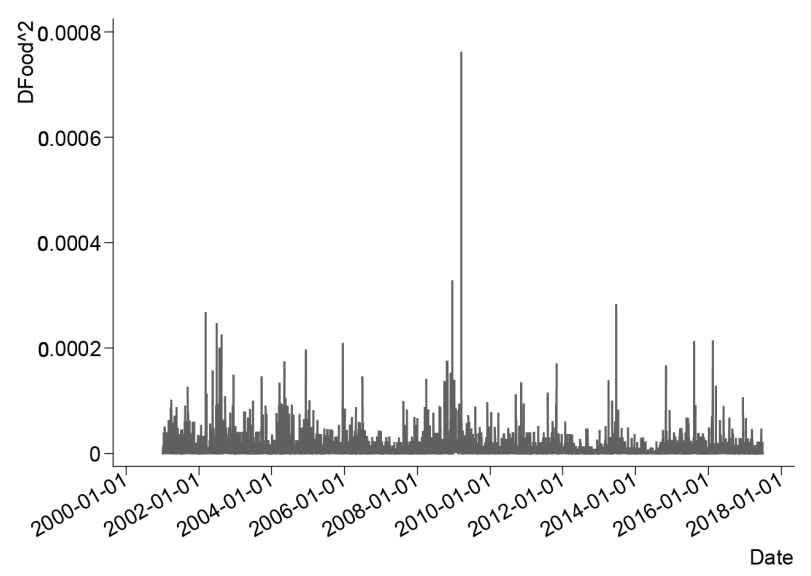

(d)

Figure 2. The time series graph of Food industry. The sample period is from January 1, 2001 to June 30, 2017.

capture the characteristics of returns' distribution and volatility, I choose the ARJI model with time-varying jumps to fit the INEER returns data.

\subsubsection{The Time-Varying Volatility and Jump Intensity}

As mentioned above, I use the daily INEER data to estimate the exchange rate volatility and jump intensity of the 13 industries between January 2, 2001 and June 30, 2017. Firstly, I test the stability of the data. The results of both DF test and PP tests show that the INEER returns series of all industries are stable at 1\% significant level. Then, I use the basic-ARJI model and ARJI- $h_{t}$ model separately to estimate the volatility and jump dynamics of daily INEER returns of the 13 industries for a total of 55,913 data. The estimation results by BFGS method show that all industries' INEER returns show convergence in the basic-ARJI model. And in addition to the metal industry, other industries also show convergence and better goodness of fit in the estimation conducted by ARJI- $h_{t}$ model. In order to maintain the amount of data and without loss of generality, this paper selects the basic-ARJI model to capture the time-varying jump intensity of different industries. Table A3 reports the estimation results of the 


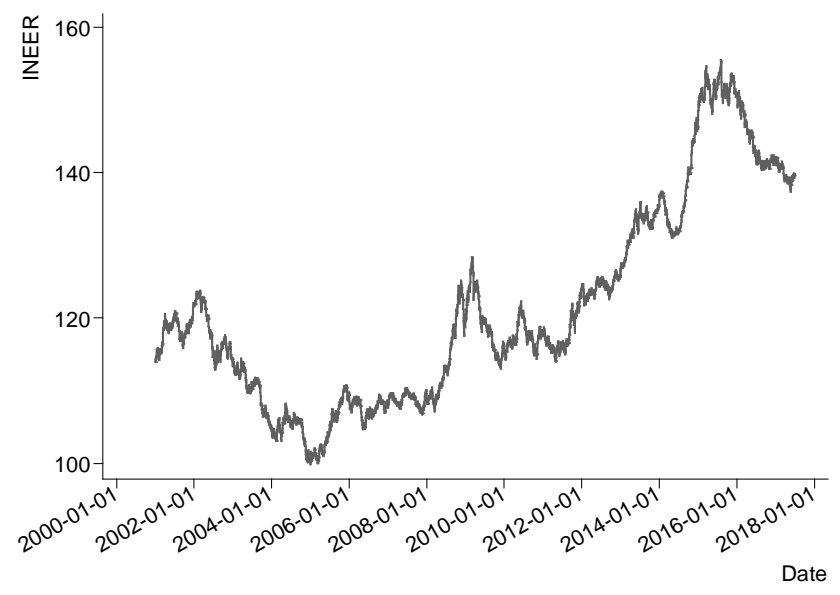

(a)

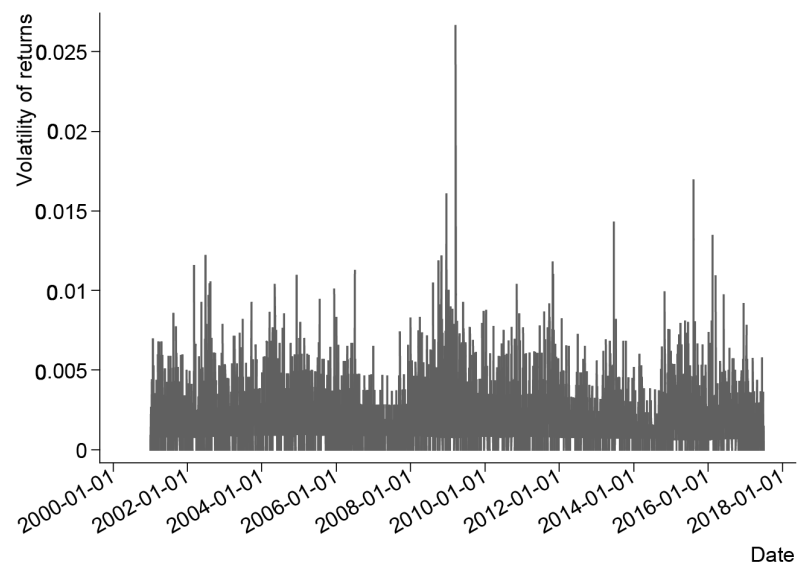

(c)

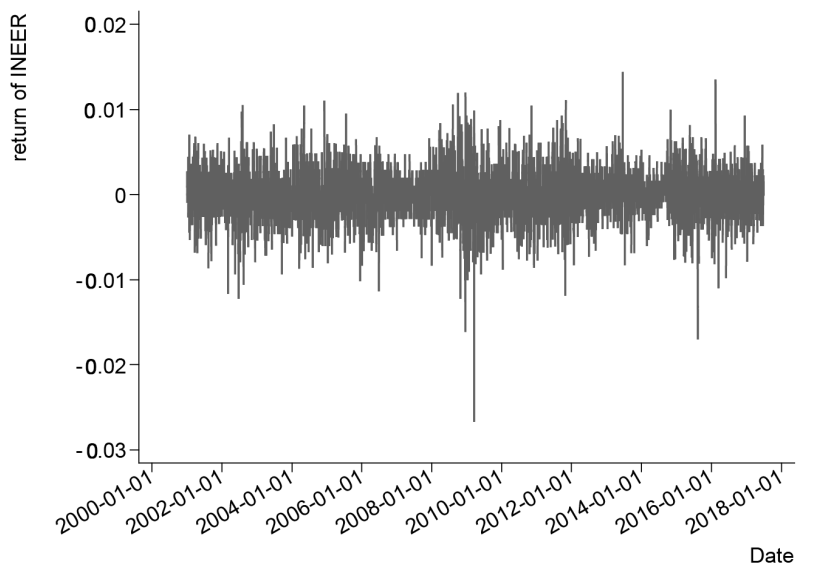

(b)

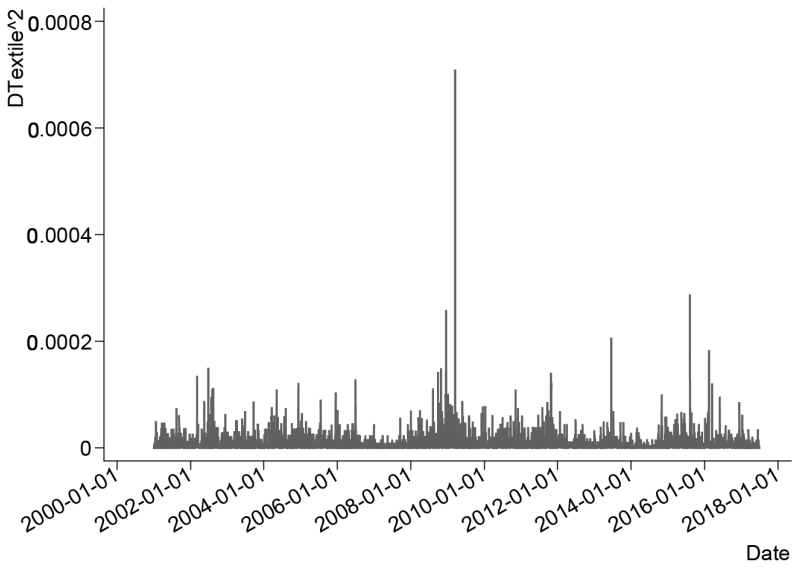

(d)

Figure 3. The time series graph of Textile industry. The sample period is from January 1, 2001 to June 30, 2017.

parameters of various industries. The parameter symbols and their meanings are consistent with those in part 3.1. And the ARJI- $h_{t}$ model is used in robustness test.

To demonstrate the efficiency of the ARJI model in capturing volatility and jump dynamics of various industries' INEER returns, I plot the volatility and jump intensity of INEER returns in the four industries of food, textile, electrical machinery and transportation equipment, which is shown in Figures 4-7 (other industries have similar graphics). Take Figure 4 as an example, it presents daily volatility and jump intensity of food industry's INEER estimated from the basic-ARJI model. Panel A for volatility, and panel B for jump intensity. The sample period is from January 2, 2001 to June 30, 2017. Table A4 reports the total conditional variance, the proportion of jump variance, and the average of the jump intensities for the INEER of various industries during the sample period estimated by the basic-ARJI model.

These graphs and charts (Figures 4-7 \& Table A4) show significant variations in nominal effective exchange rate volatility and jump intensity for different in 


\section{The volatility of Food's INEER}

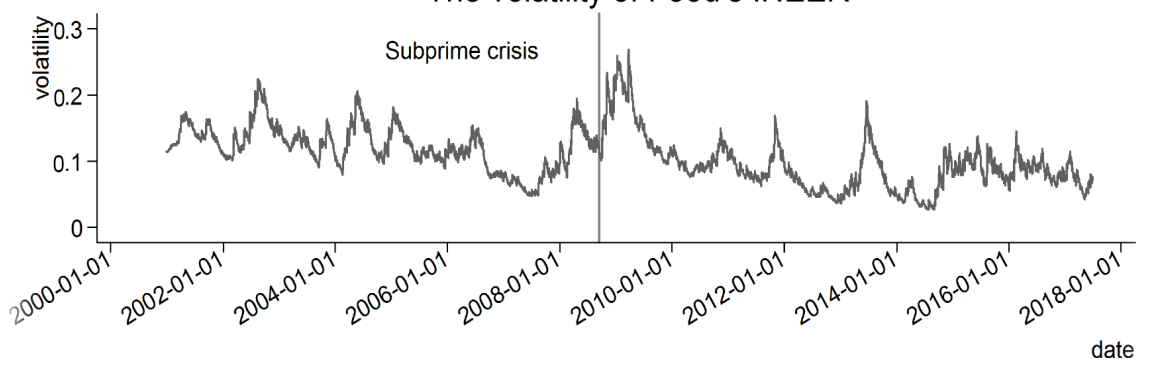

(a)

The jump intensity of Food's INEER

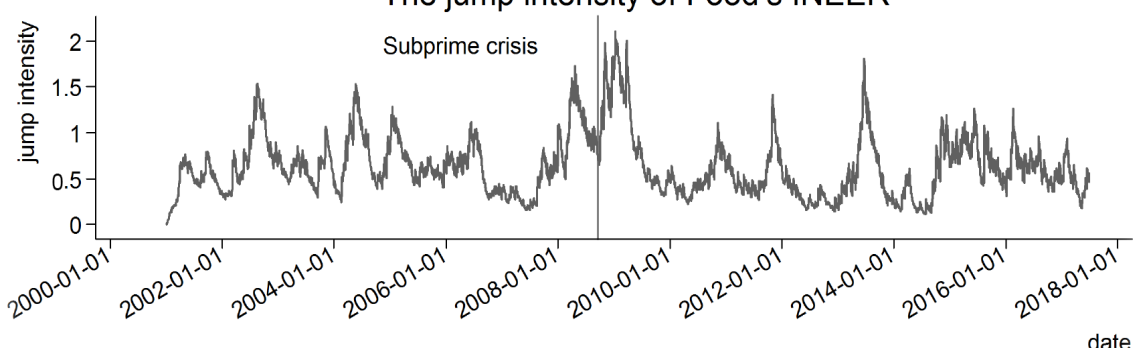

(b)

Figure 4. The volatility and jump intensity of Food's INEER. This figure presents daily volatility and jump intensity of Food industry's INEER estimated from the basic-ARJI model. Panel A for volatility, and panel B for jump intensity. The sample period is from January 2, 2001 to June 30, 2017.

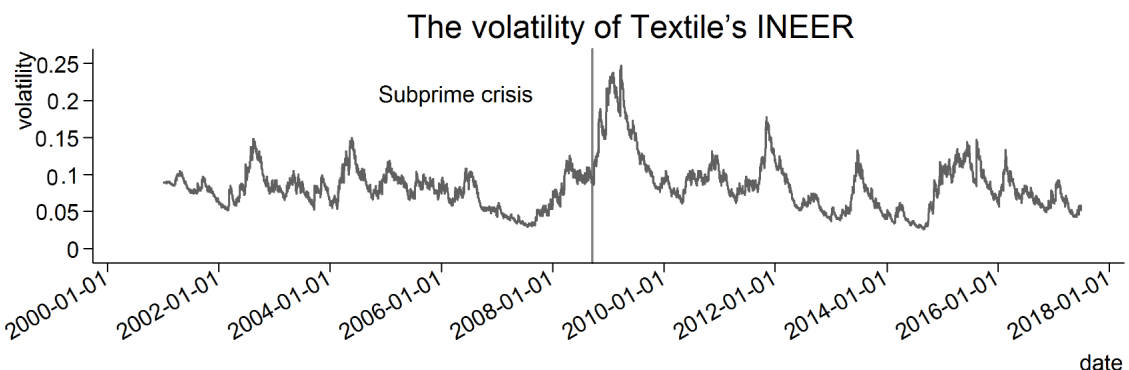

(a)

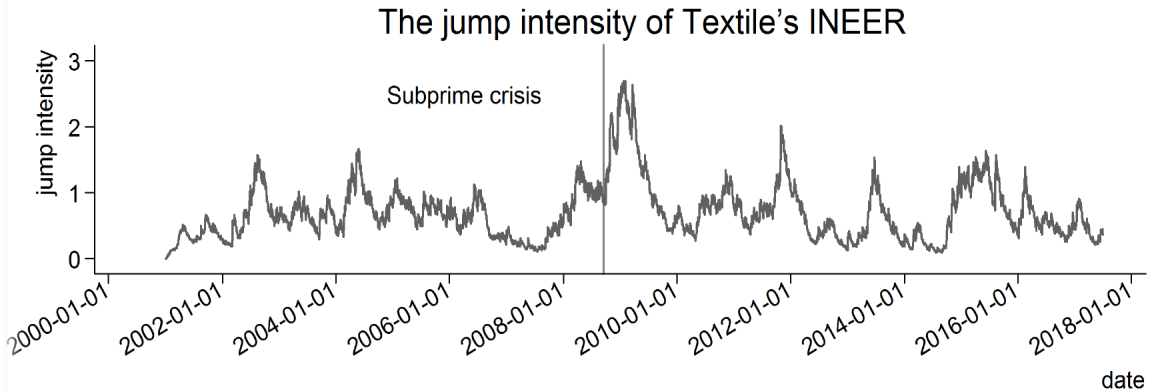

(b)

Figure 5. The volatility and jump intensity of Textile's INEER. This figure presents daily volatility and jump intensity of Textile industry's INEER estimated from the basic-ARJI model. Panel A for volatility, and panel B for jump intensity. The sample period is from January 2, 2001 to June 30, 2017. 
The volatility of Electric Machinery's INEER

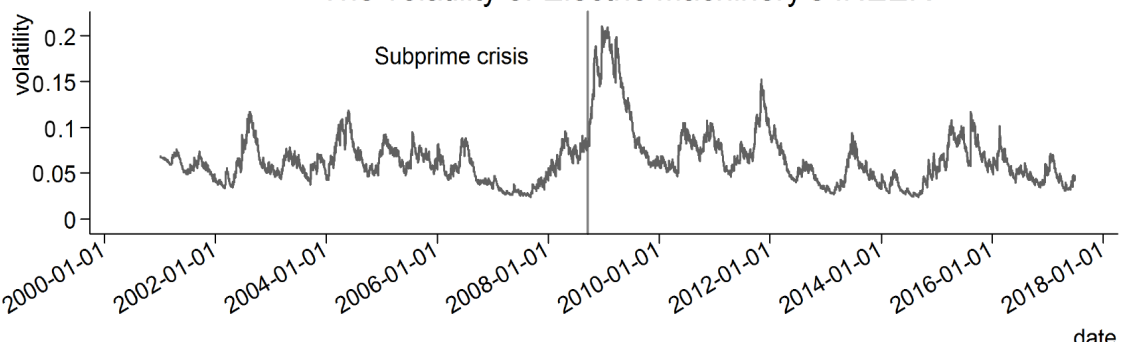

(a)

The jump intensity of Electric Machinery's INEER

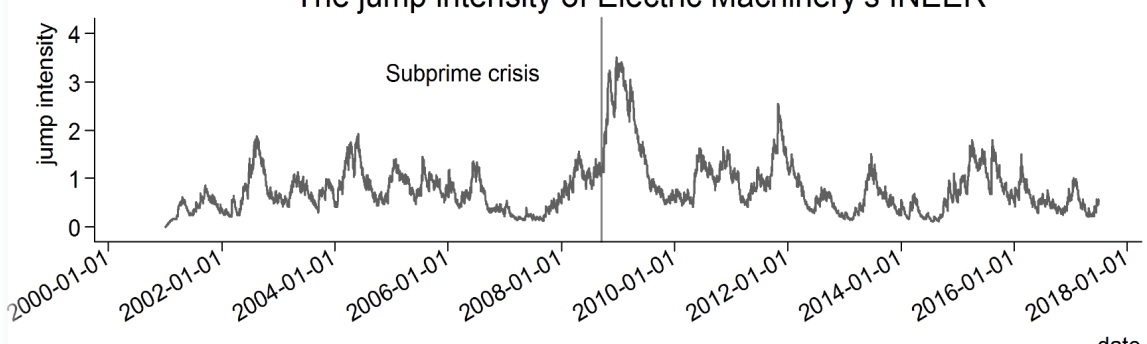

(b)

Figure 6. The volatility and jump intensity of Electric Machinery's INEER. This figure presents daily volatility and jump intensity of Electric Machinery industry's INEER estimated from the basic-ARJI model. Panel A for volatility, and panel B for jump intensity. The sample period is from January 2, 2001 to June 30, 2017.

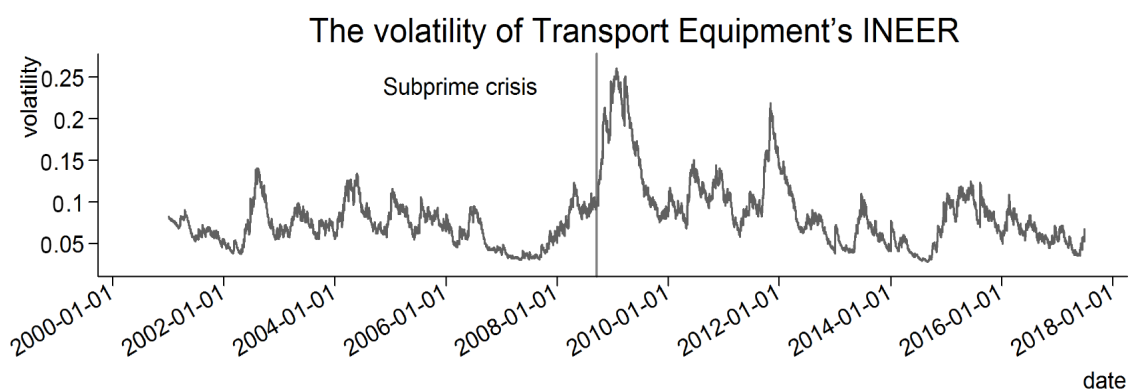

(a)

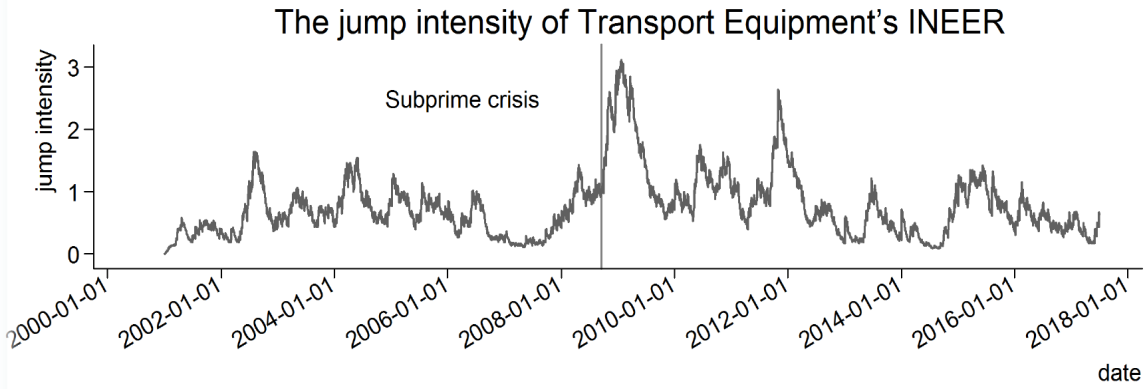

(b)

Figure 7. The volatility and jump intensity of Transport Equipment's INEER. This figure presents daily volatility and jump intensity of Transport Equipment industry's INEER estimated from the basic-ARJI model. Panel A for volatility, and panel B for jump intensity. The sample period is from January 2, 2001 to June 30, 2017. 
dustries. The daily volatility (jump intensity) ranges from 0.02698 (0.00801) to 0.26804 (2.10175) for food industry; from 0.02667 (0.00602) to 0.24697 (2.69939) for textile industry; from $0.02402(0.00723)$ to 0.21009 (3.50933) for electrical machinery; from $0.02822(0.00549)$ to 0.25998 (3.10469) for transportation equipment. A striking peak of volatility and jump intensity for all industries occurred between late 2008 and early 2009, coinciding with the timing of the U.S. subprime mortgage crisis. The bankruptcy of Lehman Brothers in September 2008 has greatly exacerbated the crisis in the U.S. banking system, and economies worldwide subsequently suffered as credit tightened and international trade declined.

There are also significant differences in the proportion of jump variance in total variance among different industries. Prior to the subprime crisis in 2008, industries with a jump variance of less than $30 \%$ of the total variance included paper, non-metal and metal industries. And industries accounting for more than $50 \%$ included petroleum, rubber, electrical machinery, optical instruments and transportation equipment, of which only the rubber industry accounted for more than $60 \%$. From the 2008 subprime crisis to the European debt crisis in 2009 , the volatility and jumping intensity of various industries generally increased, which led to the adding of food, textile, wood and transport equipment in industries whose jump variance accounting for more than $50 \%$ of the total variance. The proportion of transport equipment industry was more than $60 \%$, and the jump variance of rubber industry accounted for as high as $78.98 \%$. After the crisis, the proportion of jump variance in various industries gradually returned to the pre-crisis level.

In terms of the conditional variance, the dynamic of jump intensity and the proportion of jump variance in 13 industries' INEER returns, the paper, non-metal, and metal industries have more stable export competitiveness, while the petroleum, rubber, electrical machinery, optical instruments and transportation equipment industries' export competitiveness is easily affected by the fluctuation of RMB exchange rate. This is basically consistent with the statistical analysis of INEER. The above results also show that the ARJI model can provide a good measure of volatility and jump dynamics for the INEER of the 13 industries.

\subsection{The Impact of Major International Currencies on Exchange Rate Risk in Various Industries}

The previous section gives the volatility and jump dynamics of various industries' INEER return. In this section, I examine the impact of the U.S. dollar, German mark, and Japanese yen on the INEER fluctuations of different industries. The basic regression model is as follows:

$$
v o l_{t}^{i} / \lambda_{t}^{i}=\beta_{0}^{i}+\beta_{1}^{i} v o l \_U S D_{t}+\beta_{2}^{i} v o l \_D E M_{t}+\beta_{2}^{i} v o l \_J P Y_{t}+\varepsilon_{t}^{i}
$$

where $v_{t} l_{t}^{i} / \lambda_{t}^{i}$ represents the volatility/jump intensity of NEER at time $t$ of industry $i$. vol_USD $D_{t}$ vol_DEM ${ }_{t}$ and $v o l \_J P Y_{t}$ respectively represents the no- 
minal exchange rate volatility of $\mathrm{t}$ the U.S. dollar, German mark, and Japanese yen. $\beta_{0}^{i}$ indicates industry-specific effects, reflecting industry heterogeneity over time.

The test of stability is conducted for each variable series. Take food industry as an example, DF test and PP test results show that the INEER return volatility $\left(v o l_{t}^{1}\right)$ and the nominal exchange rate volatility of dollar $\left(v o l \_U S D_{t}\right)$ are non-stationary at $5 \%$ significant level. But all the first-order differences of variable series are stable at $1 \%$ significant level. Therefore, the first-order differential data for all the variables in Equation (16) are used for regression. I perform OLS estimation using white-robust standard error. For most industries, the goodness of fit of the model remains above $40 \%$ and the accompanying probabilities of F-test are close to 0, indicating that the regression results have a good guiding significance.

Table A5 reports the effects of major currencies on the volatility of different industries' INEER returns in different periods. Columns (1)-(3) report OLS regression results of the whole sample; columns (4)-(6) report sub-sample regression results before subprime crisis; columns (7)-(9) report sub-sample regression results after subprime crisis. In line with my expectations, the sign of most coefficients is basically positive, indicating that fluctuations in the dollar, the mark and the yen will aggravate the fluctuations in the nominal effective exchange rates of various industries.

From the horizontal comparisons of columns (1)-(3) in Table A5, I find that the impact of the U.S. dollar, German mark, and Japanese yen on the volatility of various industries' INEER weakens in turn throughout the whole sample period, where the impact of the dollar on the INEER returns of all industries is significant at $1 \%$ significant level, which may be due to the strong position of the U.S. dollar in the international arena and the fact that most of our trade partners implement the exchange rate system pegged to the U.S. dollar, besides, the fact that China and the United States have long been each other's second largest trading partner also play a part in it. Comparing the regression results before and after the financial crisis, it is easy to find that after the financial crisis, the impact of the U.S. dollar on the INEER returns volatility of various industries has obviously dropped. And except for the food industry, the influence of German mark on China's exchange rate volatility in various industries is not significant before the subprime crisis but significant after the subprime crisis. On the contrary, the impact of Japanese yen is significant before the subprime crisis but not significant after the subprime crisis. One possible reason is that the subprime crisis has led to a decline in the U.S. economy and exerted a seriously negative impact on the Japanese economy, resulting in a decline in the international position of the U.S. dollar and the Japanese yen. Meanwhile, as the German economy recovered rapidly from the financial crisis, the international status of German mark has risen greatly. These results show that the impact of the major reshuffle caused by the subprime mortgage crisis in 2008 on China's exchange rate risk is that the impact of the U.S. dollar and the Japanese yen has dropped significantly, 
and the impact of the German mark has generally risen.

In longitudinal contrast of Table A5, I find that among the 13 industries, the U.S. dollar has a significantly greater effect on non-metal, metal, general machinery and chemical industries. The reason may lie in the fact that China's exports to the United States are mainly concentrated in the machinery and equipment (accounting for $47 \%$ of total exports) and metals (8\%) industries, while United States exports to China are mainly concentrated in machinery and equipment (31\%) and chemical (8\%) industries. ${ }^{1}$ The German mark has greater impact on the INEER volatility of industries such as transportation equipment, electrical machinery, petroleum and textiles. While Japanese yen has slightly larger impact on the volatility of food industry's INEER return.

Table A6 reports the regression results of the major currencies' impact on the jump intensity of different industries' INEER returns. The sign of some coefficients is significantly negative, which indicates that sometimes the fluctuation of certain currencies could significantly reduce the exchange rate risk of these industries. The horizontal comparisons of Table A6 are basically the same as Table A5. And the differences in vertical comparisons are reflected in the significant impact of both the U.S. dollar and the German mark on exchange rate jumps in rubber, electrical machinery and transportation equipment industries during the entire sample period, which means that those industries' abnormal change in nominal exchange rate is mainly affected by the volatility of the U.S. dollar and German mark.

\section{Robustness Test}

In this section, I consider the estimated robustness and discuss my conclusions. Firstly I reduce all variables at the 1st and 90th percentiles to mitigate the effects of extreme observations. The estimation results are qualitatively similar to the main results of this paper. To save space, the estimated results will not be listed here.

In the second robustness test, the related regression is conducted by replacing the jump intensity with the jump variance (i.e. $\left.\operatorname{var}\left[C_{t} \mid \Phi_{t-1}\right]\right]$ measured by the ARJI model). Observing the results reported in Table A7, I find that the impact of the U.S. dollar, German mark, and Japanese yen on the jump variance in different industries also weaken in turn. And by comparing the results before and after the financial crisis, it is easy to conclude that the impact of the U.S. dollar on all industries has significantly reduced. And the influence of German mark on China's exchange rate volatility in various industries is not significant before the subprime crisis but significant after the subprime crisis. On the contrary, the impact of Japanese yen is significant before the subprime crisis but not significant after the subprime crisis. All of these are consistent with the main conclusions above.

In the third robustness test, I replace the time-varying jump intensity esti${ }^{1}$ Wang \& Li (2017). The Depth of China's Gold: Possibility and Impact of Sino-US Trade War. https://wallstreetcn.com/articles/283859 
mated by the basic ARJI model with the time-varying jump intensity estimated by the ARJI- $h_{t}$ model. When estimated by ARJI- $h_{t}$ model, the exchange rate of metal products industry does not turn out convergent, thus I remove it and use the remaining 12 industries to carry out regression test, the regression results of which are reported in Table A8. It turns out the conclusions are still relatively consistent with the main conclusions estimated by basic ARJI model.

Finally, I used the monthly data to carry out the regression. Table A9 and Table A10 report the monthly regression results of exchange rate volatility and jump intensity for the 13 industries. The regression results of exchange rate volatility were consistent with the main conclusions of this paper. However, at the same time, it's not hard to find that expanding the scope of time enables the regression results of the jump intensity of INEER return in many industries to be insignificant. Take the U.S. dollar as an example, it has a significant impact on the jump intensity of all industries in the daily data regression, but the monthly data regression results show that the impact of the U.S. dollar on the jump intensity of INEER return in the food, chemical and non-metal industries is not significant. Although the regression coefficient of some industries decreased in significance, the impact of the exchange rate volatility and the jump intensity of the U.S. dollar on most industries before and after the crisis is significant, and the impact after the crisis diminishes. For the textile, petroleum, general machinery and other industries, the impact of German mark was not significant prior to the crisis, but it becomes significant after the crisis; the impact of the yen on most sectors was significant prior to the crisis, but it is insignificant after the crisis. All of these indicate that the monthly regression results still support the main conclusions of this paper.

\section{Main Conclusions, Contributions, Shortcomings of Research and Expectations}

In this study, I apply the Autoregressive Jump Intensity (ARJI) model to explore the characteristics and determinants of industry-specific exchange rate risk of 13 industries in China. I find that the ARJI model performed quite well in capturing the volatility and the jump dynamics of exchange rate in foreign exchange market. Therefore, I estimate the daily exchange rate volatility and jump intensity of 13 industries' INEER return using the ARJI model. Through comparison, I find that the paper, non-metal and metal industries have relatively low exchange rate volatility and jump intensity, showing that the export competitiveness of these industries is relatively stable. However, the exchange rate volatility and jump intensity in industries of petroleum, rubber, electrical machinery, optical instruments and transportation equipment show that their export competitiveness is vulnerable to the impact of $\mathrm{RMB}$ exchange rate fluctuations.

More importantly, I find that fluctuations in major international currencies such as the U.S. dollar, German mark, and the Japanese yen have significantly different effects on the risk of exchange rate fluctuations in different industries over different periods of time. First, from January 1, 2001 to June 30, 2017, the 
impact of the dollar, the mark and the yen on the volatility and jump intensity of INEER of various industries weakens in turn. Second, the impact of the major reshuffle caused by the subprime mortgage crisis in 2008 on China's exchange rate risk is that the impact of the U.S. dollar and the Japanese yen has dropped significantly, and the impact of the German mark has generally risen. Third, among the 13 manufacturing industries studied in this paper, the U.S. dollar has a significantly greater effect on non-metal, metal, general machinery and chemical industries, while German mark has greater impact on the INEER volatility of industries such as transportation equipment, electrical machinery, petroleum and textiles, and Japanese yen has slightly larger impact on the volatility of food industry's INEER return.

This paper contributes to the existing literature and real economy in two aspects. First, to the best of my knowledge, this is the first comprehensive study to explore the jump intensity of industry-specific exchange rate. Different from the existing measures of exchange rate volatility, this paper provides a more adequate measurement of exchange rate volatility and the occasional exchange rate jumps. Besides, it proves that different industries in China are facing different degrees of exchange rate risk. Second, the empirical study in this paper shows that the volatility of international currencies such as the U.S. dollar, German mark and Japanese yen have quite different influence on exchange rate risk of various manufacturing segments in China. And the conclusion of this paper is of great significance to the government departments and enterprises in promoting industrial internationalization, accelerating industrial restructuring and upgrading and implementing sub-industry exchange rate risk management.

The shortcoming of this paper is that although it points out the different impacts of the volatility of the U.S. dollar, German mark and Japanese yen on the risk of exchange rate fluctuations in different industries over different periods, due to the lack of research data, the impact mechanism has not yet been discussed in depth. In the future, I expect to make efforts in the mechanism research and carry out further research on the impact of INEER returns' volatility and jump risk on the industry-specific stock market returns, profit margins and import and export.

\section{References}

Akgiray, V., \& Booth, G. G. (1988). Mixed Diffusion-Jump Process Modeling of Exchange Rate Movements. Review of Economics \& Statistics, 70, 631-637. https://doi.org/10.2307/1935826

Ball, C. A., \& Torous, W. N. (1983). Bond Price Dynamics and Options. Journal of Financial \& Quantitative Analysis, 18, 517-531. https://doi.org/10.2307/2330945

Bates, D. S. (1991). The Crash of '87: Was It Expected? The Evidence from Options Markets. Journal of Finance, 46, 1009-1044. https://doi.org/10.1111/j.1540-6261.1991.tb03775.x

Bayoumi, T., \& Eichengreen, B. (1998). Exchange Rate Volatility and Intervention: Implications of the Theory of Optimum Currency Areas. Journal of International Economics, 45, 191-209. https://doi.org/10.1016/S0022-1996(98)00032-4 
Bollerslev, T. P. (1986). Generalized Autoregressive Conditional Heteroskedasticity with Applications in Finance. General Information, 31, 307-327.

Bollerslev, T., Law, T. H., \& Tauchen, G. (2008). Risk, Jumps, and Diversification. Journal of Econometrics, 144, 234-256. https://doi.org/10.1016/j.jeconom.2008.01.006

Chan, W. H., \& Maheu, J. M. (2002). Conditional Jump Dynamics in Stock Market Returns. Journal of Business \& Economic Statistics, 20, 377-389. https://doi.org/10.1198/073500102288618513

Chen, B. K., Wan, X. L., \& Fu, X. G. (2010). RMB Exchange Rate, Export Prices and China's Export Competitiveness-A Study Based on Industry-Level Data. Journal of Financial Research, No. 12, 30-42.

Chernov, M., Gallant, A. R., Ghysels, E., \& Tauchen, G. (1999). A New Class of Stochastic Volatility Models with Jumps: Theory and Estimation. https://ssrn.com/abstract $=189628$

Das, S. R. (1998). Poisson-Gaussian Processes and the Bond Market. NBER Working Paper No. 6631, Cambridge, MA: National Bureau of Economic Research. https://doi.org/10.3386/w6631

Devereux, M. B., \& Engel, C. (2002). Exchange Rate Pass-Through, Exchange Rate Volatility, and Exchange Rate Disconnect. Journal of Monetary Economics, 49, 913-940. https://doi.org/10.1016/S0304-3932(02)00130-7

Engle, R. F. (1982). Autoregressive Conditional Heteroscedasticity with Estimates of the Variance of United Kingdom Inflation. Econometrica, 50, 987-1007. https://doi.org/10.2307/1912773

Engle, R. F., Lilien, D. M., \& Robins, R. P. (1987). Estimating Time Varying Risk Premia in the Term Structure: The Arch-M Model. Econometrica, 55, 391-407. https://doi.org/10.2307/1913242

Eraker, B., Johannes, M., \& Polson, N. (2003). The Impact of Jumps in Volatility and Returns. Journal of Finance, 58, 1269-1300. https://doi.org/10.1111/1540-6261.00566

Fazio, G., Mcadam, P., \& Macdonald, R. (2007). Disaggregate Real Exchange Rate Behaviour. Open Economies Review, 18, 389-404. https://doi.org/10.1007/s11079-007-9055-3

Fortune, P. (1999). Are Stock Returns Different over Weekends? A Jump Diffusion Analysis of the "Weekend Effect". New England Economic Review, 10, 3-19.

Frankel, J. A., \& Wei, S .J. (1994). Yen Bloc or Dollar Bloc? Exchange Rate Policies of the EAST ASIAN ECONomies. In T. Ito, \& A. O. Krueger, (Eds.), Macroeconomic Linkage: Savings, Exchange Rates, and Capital Flows, Chicago, IL: University of Chicago Press.

Giannellis, N., \& Papadopoulos, A. P. (2011). What Causes Exchange Rate Volatility? Evidence from Selected EMU Members and Candidates for EMU Membership Countries. Journal of International Money \& Finance, 30, 39-61. https://doi.org/10.1016/j.jimonfin.2010.07.002

Glosten, L. R., Jagannathan, R., \& Runkle, D. E. (1993). On the Relation between the Expected Value and the Volatility of the Nominal Excess Return on Stocks. Staff Report, $48,1779-1801$.

Goldberg, L. S. (2004). Industry-Specific Exchange Rates for the United States. Economic Policy Review, 10, 1-16.

Hsieh, D. A. (1989). Modeling Heteroscedasticity in Daily Foreign-Exchange Rates. Journal of Business \& Economic Statistics, 7, 307-317.

Jorion, P. (1988). On Jump Processes in the Foreign Exchange and Stock Markets. Review 
of Financial Studies, 1, 427-445. https://doi.org/10.1093/rfs/1.4.427

Li, G. Z., Zhu, J. Q., \& Li, J. (2016). Understanding Bilateral Exchange Rate Risks. Journal of International Money \& Finance, 68, 103-129. https://doi.org/10.1016/j.jimonfin.2016.07.008

Li, J., Li, G., \& Zhou, Y. (2015). Do Securitized Real Estate Markets Jump? International Evidence. Pacific-Basin Finance Journal, 31, 13-35. https://doi.org/10.1016/j.pacfin.2014.11.001

Maheu, J. M., \& Mccurdy, T. H. (2004). News Arrival, Jump Dynamics, and Volatility Components for Individual Stock Returns. Journal of Finance, 59, 755-793. https://doi.org/10.1111/j.1540-6261.2004.00648.x

Press, S. J. (1967). A Compound Events Model for Security Prices. Journal of Business, 40, 317-335. https://doi.org/10.1086/294980

Sato, K., Shimizu, J., Shrestha, N., \& Zhang, S. (2013). Industry-Specific Real Effective Exchange Rates and Export Price Competitiveness: The Cases of Japan, China, and Korea. Asian Economic Policy Review, 8, 298-321. https://doi.org/10.1111/aepr.12032

Sato, K., Shimizu, J., Shrestha, N., \& Zhang, S. (2015). Industry-Specific Real Effective Exchange Rates in Asia. Discussion Papers, Japan: Research Institute of Economy, Trade and Industry (RIETI).

Tong, H. F., \& Liu, H. W. (2006). An Empirical Analysis of the Jumping Characteristic of the Return and Volatility of Chinese Stock Market. South China Journal of Economics No. 5, 61-72.

Tucker, A. L., \& Pond, L. (1988). The Probability Distribution of Foreign Exchange Price Changes: Tests of Candidate Processes. Review of Economics \& Statistics, 70, 638-647. https://doi.org/10.2307/1935827

Vlaar, P. G., \& Palm, F. (1993). The Message in Weekly Exchange Rates in the European Monetary System: Mean Reversion, Conditional Heteroscedasticity, and Jumps. Journal of Business \& Economic Statistics, 11, 351-360.

Wang, H. F., \& Li, Q. S. (2017). The Depth of China's Gold: Possibility and Impact of Sino-US Trade War. https://wallstreetcn.com/articles/283859

Wolff, C. C., Nieuwland, F. G. M. C., \& Verschoor, W. F. C. (1994). Stochastic Jumps in EMS Exchange Rates. Journal of International Money \& Finance, 13, 699-727. https://doi.org/10.1016/0261-5606(94)90039-6

$\mathrm{Xu}$, J. W., \& Tian, F. (2013). Calculation of Industry-Specific Real Effective Exchange Rate in China: from 2000 to 2009. The Journal of World Economy, No. 5, 21-36.

Yang, Z. Y., \& Chen, L. N. (2001). Index Option Model Based on Jump Process. Economic Research Journal, No. 2, 61-66.

Zou, H. Y., You, J., \& Fu, X. (2016). The Industry-Specific Nominal Effective Exchange Rate of RMB and Its Impact on the Rate of Industry-specific Returns. Microeconomics, No. 4, 88-96. 


\section{Appendix A}

Table A1. Industry classification corresponding to the international and domestic industry classification.

\begin{tabular}{|c|c|c|c|c|}
\hline Code & Industry & Description & ISIC.Rev3 & $\begin{array}{c}\text { Guidelines for Industry } \\
\text { Classification of Listed } \\
\text { Companies (revised in 2012) }\end{array}$ \\
\hline 1 & Food & Food, Beverage, and Tobacco & $15-16$ & $\mathrm{C} 13-\mathrm{C} 16$ \\
\hline 2 & Textile & Texiles, Texile Product, Leather, and Footwear & $17-19$ & $\mathrm{C} 17-\mathrm{C} 19$ \\
\hline 3 & Wood & Wood Products (excl.Furniture) & 20 & $\mathrm{C} 20$ \\
\hline 4 & Paper & Paper, Paper Products, Printing, and Publishing & $21-22$ & $\mathrm{C} 22-\mathrm{C} 23$ \\
\hline 5 & Petroleum & Coke, Refined Petroleum|Products, and Nuclear Fuel & 23 & $\mathrm{C} 25$ \\
\hline 6 & Chemical & Chemicals and Chemical Products & 24 & $\mathrm{C} 26-\mathrm{C} 28$ \\
\hline 7 & Rubber & Rubber and Plastics Products & 25 & C29 \\
\hline 8 & Non-Metal & Non-metallic Mineral Products & 26 & $\mathrm{C} 30$ \\
\hline 9 & Metal & Basic Metals and Fabricated Metal Products & $27-28$ & C31-C33 \\
\hline 10 & General Machinery & Machinery and Equipment n.e.c & 29 & C34-C35, C41 \\
\hline 11 & Electric Machinery & Electrical Machinery and Apparatus n.e.c & $30-32$ & C38-C39 \\
\hline 12 & Optical & Optical and Precision Instruments & 33 & C40 \\
\hline 13 & $\begin{array}{l}\text { Transport Equip- } \\
\text { ment }\end{array}$ & Transport Equipment & $34-35$ & C36-C37 \\
\hline
\end{tabular}

Table A2. The statistical analysis of INEER (2001/1/1-2017/6/30).

\begin{tabular}{|c|c|c|c|c|c|c|c|c|c|c|c|c|c|}
\hline & Food & Textile & Wood & Paper & Petroleum & Chemical & Rubber & Non-Metal & Metal & $\begin{array}{c}\text { General } \\
\text { Machinery }\end{array}$ & $\begin{array}{c}\text { Electric } \\
\text { Machinery }\end{array}$ & $\begin{array}{c}\text { Optical } \\
\text { Instruments }\end{array}$ & $\begin{array}{l}\text { Transport } \\
\text { Equipment }\end{array}$ \\
\hline Mean & 120.089 & 121.092 & 119.9303 & 118.4087 & 123.5415 & 123.3652 & 119.6221 & 120.4678 & 121.0066 & 122.0695 & 119.9476 & 121.1536 & 120.0526 \\
\hline Maximum & 152.9 & 155.5 & 149.1 & 146 & 157.7 & 158.4 & 148.9 & 151.8 & 152.4 & 156.9 & 149.1 & 152.4 & 153.1 \\
\hline Minimum & 99.3 & 99.7 & 99.5 & 99.1 & 99.3 & 99.2 & 99.7 & 99.5 & 99.4 & 99.7 & 99.7 & 99.6 & 99 \\
\hline $\begin{array}{l}\text { Standard } \\
\text { deviation }\end{array}$ & 12.50542 & 14.01405 & 12.0492 & 12.02828 & 14.32972 & 15.71129 & 12.88895 & 13.55559 & 13.80055 & 15.09662 & 12.67317 & 13.18307 & 13.67427 \\
\hline
\end{tabular}

Data source: RIETI database. 
Table A3. The basic ARJI mode's parameters estimation results of INEER returns.

\begin{tabular}{|c|c|c|c|c|c|c|c|c|c|c|c|c|c|}
\hline Parameters & Food & Texile & Wood & Paper & Petroleum & Chemical & Rubber & Non-Metal & Metal & $\begin{array}{c}\text { General } \\
\text { Machinery }\end{array}$ & $\begin{array}{c}\text { Electric } \\
\text { Machinery }\end{array}$ & $\begin{array}{c}\text { Optical } \\
\text { Instruments }\end{array}$ & $\begin{array}{l}\text { Transport } \\
\text { Equipment }\end{array}$ \\
\hline \multirow[t]{2}{*}{$\mu$} & 0.0103 & 0.0102 & 0.0127 & 0.0080 & 0.0094 & 0.0022 & 0.0077 & 0.0083 & 0.0059 & 0.0049 & 0.0048 & 0.0089 & 0.0042 \\
\hline & $(0.0261)$ & $(0.0051)$ & $(0.0076)$ & $(0.0329)$ & $(0.0703)$ & $(0.6954)$ & $(0.0763)$ & $(0.0354)$ & $(0.1390)$ & $(0.2990)$ & $(0.2896)$ & $(0.0670)$ & $(0.3890)$ \\
\hline \multirow[t]{2}{*}{$\phi_{1}$} & -0.0432 & -0.0553 & -0.0596 & -0.0449 & -0.0357 & -0.0082 & -0.0727 & -0.0260 & 0.0029 & -0.0458 & -0.0523 & -0.0424 & -0.0475 \\
\hline & $(0.0030)$ & $(0.0001)$ & $(0.0001)$ & $(0.0030)$ & $(0.0172)$ & $(0.5884)$ & $(0.0000)$ & $(0.0903)$ & $(0.8559)$ & $(0.0032)$ & $(0.0006)$ & $(0.0064)$ & $(0.0019)$ \\
\hline$\phi_{2}$ & $(0.7354)$ & $(0.9415)$ & $(0.9069)$ & $(0.7655)$ & $(0.3084)$ & $(0.8133)$ & $(0.9151)$ & $(0.8654)$ & $(0.9987)$ & $(0.7745)$ & $(0.5469)$ & $(0.2008)$ & $(0.3980)$ \\
\hline \multirow[t]{2}{*}{$\omega$} & 0.0000 & 0.0000 & 0.0000 & 0.0002 & 0.0001 & -0.0001 & 0.0002 & 0.0001 & 0.0002 & 0.0001 & 0.0001 & 0.0000 & 0.0002 \\
\hline & $(0.1276)$ & $(0.4905)$ & $(0.8759)$ & $(0.1280)$ & $(0.3719)$ & $(0.7823)$ & $(0.0940)$ & $(0.1268)$ & $(0.0741)$ & $(0.3992)$ & $(0.2217)$ & $(0.5343)$ & $(0.1211)$ \\
\hline \multirow[t]{2}{*}{$\alpha_{1}$} & 0.0019 & 0.0020 & 0.0020 & 0.0216 & 0.0035 & 0.0264 & 0.0005 & 0.0264 & 0.0311 & 0.0238 & 0.0021 & 0.0018 & 0.0022 \\
\hline & $(0.0118)$ & $(0.0386)$ & $(0.0101)$ & $(0.0000)$ & $(0.1056)$ & $(0.0000)$ & $(0.7601)$ & $(0.0000)$ & $(0.0000)$ & $(0.0000)$ & $(0.1540)$ & $(0.0722)$ & $(0.0077)$ \\
\hline$\beta_{1}$ & $(0.0000)$ & $(0.0000)$ & $(0.0000)$ & $(0.0000)$ & $(0.0000)$ & $(0.0000)$ & $(0.0000)$ & $(0.0000)$ & $(0.0000)$ & $(0.0000)$ & $(0.0000)$ & $(0.0000)$ & $(0.0000)$ \\
\hline \multirow[t]{2}{*}{$\zeta_{0}$} & 0.2950 & 0.2530 & 0.2763 & 0.3106 & 0.2683 & 0.2402 & 0.1678 & 0.3324 & 0.3419 & 0.2885 & 0.2121 & 0.2202 & 0.2507 \\
\hline & $(0.0000)$ & $(0.0000)$ & $(0.0000)$ & $(0.0000)$ & $(0.0000)$ & $(0.0000)$ & $(0.0000)$ & $(0.0000)$ & $(0.0000)$ & $(0.0000)$ & $(0.0000)$ & $(0.0000)$ & $(0.0000)$ \\
\hline \multirow[t]{2}{*}{$\eta_{0}$} & -0.0067 & -0.0064 & -0.0134 & -0.0247 & -0.0070 & 0.0048 & -0.0025 & -0.0320 & -0.0294 & -0.0059 & -0.0008 & -0.0048 & 0.0002 \\
\hline & $(0.4759)$ & $(0.3674)$ & $(0.1873)$ & $(0.2916)$ & $(0.3672)$ & $(0.7169)$ & $(0.5012)$ & $(0.1760)$ & $(0.3415)$ & $(0.7836)$ & $(0.9003)$ & $(0.4192)$ & $(0.9796)$ \\
\hline \multirow[t]{2}{*}{$\lambda_{0}$} & 0.0080 & 0.0060 & 0.0070 & 0.0634 & 0.0062 & 0.1639 & 0.0090 & 0.0510 & 0.0457 & 0.0869 & 0.0072 & 0.0084 & 0.0055 \\
\hline & $(0.0134)$ & $(0.0267)$ & $(0.0094)$ & $(0.0000)$ & $(0.0201)$ & $(0.2881)$ & $(0.0165)$ & $(0.0000)$ & $(0.3034)$ & $(0.4295)$ & $(0.0182)$ & $(0.0090)$ & $(0.0096)$ \\
\hline \multirow[t]{2}{*}{$\rho$} & 0.9872 & 0.9912 & 0.9868 & 0.5860 & 0.9910 & 0.5928 & 0.9932 & 0.6672 & 0.6023 & 0.5996 & 0.9909 & 0.9896 & 0.9927 \\
\hline & $(0.0000)$ & $(0.0000)$ & $(0.0000)$ & $(0.0000)$ & $(0.0000)$ & $(0.0742)$ & $(0.0000)$ & $(0.0000)$ & $(0.0827)$ & $(0.2029)$ & $(0.0000)$ & $(0.0000)$ & $(0.0000)$ \\
\hline$\gamma$ & 0.1660 & 0.1772 & 0.1743 & 0.0469 & 0.1457 & -0.0867 & 0.1994 & -0.0371 & -0.0769 & -0.0387 & 0.2081 & 0.1803 & 0.1706 \\
\hline
\end{tabular}

Note: The value in parentheses is the $\mathrm{p}$ value.

Table A4. Statistics on the volatility and jump intensity of various industries in different periods.

\begin{tabular}{|c|c|c|c|c|c|c|c|c|c|}
\hline & \multicolumn{3}{|c|}{$2001 / 1 / 1-2008 / 9 / 15$} & \multicolumn{3}{|c|}{$2008 / 9 / 16-2009 / 12 / 15$} & \multicolumn{3}{|c|}{$2009 / 12 / 16-2017 / 6 / 30$} \\
\hline & TCV & PJV & LAM & TCV & PJV & LAM & TCV & PJV & LAM \\
\hline Food & 0.1225 & $45.65 \%$ & 0.6573 & 0.1624 & $50.87 \%$ & 1.0126 & 0.0811 & $55.24 \%$ & 0.5356 \\
\hline Textile & 0.0798 & $48.87 \%$ & 0.6362 & 0.1504 & $57.09 \%$ & 1.4187 & 0.0779 & $49.88 \%$ & 0.6513 \\
\hline Wood & 0.0885 & $44.85 \%$ & 0.5351 & 0.1247 & $53.03 \%$ & 0.9271 & 0.0694 & $48.93 \%$ & 0.4735 \\
\hline Paper & 0.0526 & $29.77 \%$ & 0.1527 & 0.1021 & $17.02 \%$ & 0.1546 & 0.0546 & $29.27 \%$ & 0.1531 \\
\hline Petroleum & 0.0993 & $53.35 \%$ & 0.7655 & 0.1636 & $51.45 \%$ & 1.2190 & 0.0706 & $50.99 \%$ & 0.5215 \\
\hline Chemical & 0.0678 & $36.78 \%$ & 0.4019 & 0.1507 & $19.04 \%$ & 0.3984 & 0.0660 & $38.40 \%$ & 0.4033 \\
\hline Rubber & 0.0465 & $60.65 \%$ & 1.0427 & 0.0974 & $78.98 \%$ & 2.7935 & 0.0533 & $66.21 \%$ & 1.3234 \\
\hline Non-Metal & 0.0656 & $27.82 \%$ & 0.1532 & 0.1650 & $13.07 \%$ & 0.1519 & 0.0705 & $27.23 \%$ & 0.1533 \\
\hline General Machinery & 0.0616 & $31.05 \%$ & 0.2171 & 0.1334 & $15.78 \%$ & 0.2154 & 0.0663 & $29.86 \%$ & 0.2174 \\
\hline Electric Machinery & 0.0597 & $50.10 \%$ & 0.7054 & 0.1262 & $59.49 \%$ & 1.7876 & 0.0604 & $51.09 \%$ & 0.7395 \\
\hline Optical Instruments & 0.0712 & $53.55 \%$ & 0.8107 & 0.1196 & $58.32 \%$ & 1.5294 & 0.0591 & $54.52 \%$ & 0.6989 \\
\hline Transport Equipment & 0.0708 & $51.47 \%$ & 0.6173 & 0.1590 & $64.27 \%$ & 1.6934 & 0.0798 & $53.90 \%$ & 0.7405 \\
\hline
\end{tabular}

Note: To avoid the influence of the initial value on the above statistical indicators, we discarded the data for the first 4 days of each industry. TVP, PJV and LAM represent the total conditional variance, the proportion of jump variance, and the average of the jump intensity respectively. 
Table A5. The daily regression results of the major currencies' influence on the INEER returns' volatility of various industries at different periods.

\begin{tabular}{|c|c|c|c|c|c|c|c|c|c|}
\hline & \multicolumn{3}{|c|}{$2001 / 1 / 1-2017 / 6 / 30$} & \multicolumn{3}{|c|}{$2001 / 1 / 1-2008 / 9 / 15$} & \multicolumn{3}{|c|}{$2008 / 9 / 16-2017 / 6 / 30$} \\
\hline & USD & DEM & JPY & USD & DEM & JPY & USD & DEM & JPY \\
\hline \multirow[t]{2}{*}{ Food } & $0.10057^{* * *}$ & $0.09323^{* *}$ & $0.01821^{* * *}$ & $0.23047^{* * *}$ & $-0.40444^{*}$ & $0.06306^{* * *}$ & $0.08395^{\star * *}$ & $0.11773^{* * *}$ & $0.01305^{* * *}$ \\
\hline & $(5.37)$ & $(2.23)$ & $(4.93)$ & $(10.38)$ & $(-1.67)$ & $(6.58)$ & $(4.31)$ & $(2.65)$ & $(4.28)$ \\
\hline \multirow[t]{2}{*}{ Textile } & $0.12554^{\star * *}$ & $0.15083^{* * *}$ & $0.00396^{\star}$ & $0.23795^{\star * *}$ & -0.21810 & $0.02795^{\star * *}$ & $0.11047^{\star * *}$ & $0.16898^{\star * *}$ & 0.00132 \\
\hline & $(9.71)$ & $(3.85)$ & $(1.85)$ & (14.88) & $(-1.00)$ & $(5.10)$ & $(9.35)$ & $(4.10)$ & $(0.76)$ \\
\hline \multirow[t]{2}{*}{ Wood } & $0.12419^{* * *}$ & $0.14528^{* * *}$ & $0.00659^{* *}$ & $0.24689^{* * *}$ & -0.26933 & $0.03661^{\star * *}$ & $0.10786^{* * *}$ & $0.16543^{\star * *}$ & 0.00323 \\
\hline & $(9.35)$ & $(3.81)$ & $(2.33)$ & $(13.82)$ & $(-1.16)$ & $(5.62)$ & $(9.30)$ & $(4.15)$ & $(1.36)$ \\
\hline \multirow[t]{2}{*}{ Paper } & $0.13301^{* * *}$ & $0.04609^{* *}$ & $0.00314^{\star *}$ & $0.19043^{* * *}$ & -0.19354 & $0.01545^{\star * *}$ & $0.12607^{* * *}$ & $0.06109^{* * *}$ & 0.00178 \\
\hline & $(8.42)$ & $(2.16)$ & $(1.98)$ & (14.06) & $(-1.46)$ & $(3.01)$ & $(6.68)$ & $(2.96)$ & $(1.28)$ \\
\hline \multirow[t]{2}{*}{ Petroleum } & $0.11756^{\star * *}$ & $0.15634^{* * *}$ & $0.00445^{\star}$ & $0.24255^{\star * *}$ & 0.05926 & $0.02315^{\star * *}$ & $0.09634^{\star * *}$ & $0.14343^{\star * *}$ & 0.00249 \\
\hline & $(8.20)$ & $(3.18)$ & $(1.75)$ & $(15.37)$ & $(0.21)$ & $(4.81)$ & $(6.54)$ & (2.99) & $(1.08)$ \\
\hline \multirow[t]{2}{*}{ Chemical } & $0.14393^{* * *}$ & $0.06983^{* *}$ & 0.00171 & $0.15419^{* * *}$ & -0.02316 & $0.00703^{\star *}$ & $0.14338^{* * *}$ & $0.07733^{\star *}$ & 0.00109 \\
\hline & $(5.30)$ & $(2.05)$ & (1.15) & (13.60) & $(-0.20)$ & $(2.12)$ & $(4.49)$ & $(2.17)$ & $(0.70)$ \\
\hline \multirow[t]{2}{*}{ Rubber } & $0.08208^{* * *}$ & $0.08469^{* * *}$ & 0.00095 & $0.14782^{* * *}$ & -0.01500 & $0.00510^{*}$ & $0.07171^{\star * *}$ & $0.08486^{* * *}$ & 0.00062 \\
\hline & $(9.74)$ & $(3.91)$ & $(1.12)$ & (18.99) & $(-0.11)$ & $(1.75)$ & (10.15) & $(4.22)$ & $(0.79)$ \\
\hline \multirow[t]{2}{*}{ Non-Metal } & $0.17951^{* * *}$ & $0.06908^{* *}$ & 0.00177 & $0.17850^{* * *}$ & -0.13681 & $0.01313^{* * *}$ & $0.18253^{* * *}$ & $0.08938^{* * *}$ & 0.00037 \\
\hline & $(7.05)$ & $(2.10)$ & (1.08) & (13.55) & $(-0.99)$ & $(2.75)$ & $(6.20)$ & $(2.75)$ & $(0.24)$ \\
\hline \multirow[t]{2}{*}{ Metal } & $0.19110^{* * *}$ & 0.02746 & 0.00265 & $0.15757^{\star * *}$ & -0.08598 & $0.00615^{*}$ & $0.19870^{* * *}$ & 0.04435 & 0.00212 \\
\hline & $(7.61)$ & $(0.83)$ & (1.17) & (14.59) & $(-0.71)$ & $(1.72)$ & (6.98) & $(1.42)$ & $(0.87)$ \\
\hline \multirow{2}{*}{$\begin{array}{c}\text { General } \\
\text { Machinery }\end{array}$} & $0.14515^{* * *}$ & $0.10863^{* * *}$ & 0.00062 & $0.13902^{\star * *}$ & 0.05045 & 0.00500 & $0.14703^{* * *}$ & $0.11494^{* * *}$ & 0.00006 \\
\hline & $(5.71)$ & $(3.30)$ & $(0.49)$ & (14.70) & $(0.41)$ & $(1.46)$ & $(4.97)$ & $(3.42)$ & $(0.05)$ \\
\hline \multirow[t]{2}{*}{$\begin{array}{c}\text { Electric } \\
\text { Machinery }\end{array}$} & $0.10985^{\star * *}$ & $0.15873^{\star * *}$ & 0.00180 & $0.20766^{\star * *}$ & -0.03909 & $0.01087^{* *}$ & $0.09511^{* * *}$ & $0.16378^{* * *}$ & 0.00095 \\
\hline & $(9.56)$ & $(4.81)$ & $(1.40)$ & (16.58) & $(-0.20)$ & $(2.38)$ & $(9.82)$ & $(5.08)$ & $(0.81)$ \\
\hline \multirow[t]{2}{*}{$\begin{array}{c}\text { Optical } \\
\text { Instruments }\end{array}$} & $0.09365^{* * *}$ & $0.10420^{\star * *}$ & $0.00348^{\star}$ & $0.19822^{\star * *}$ & -0.09223 & $0.02021^{* * *}$ & $0.07757^{* * *}$ & $0.10606^{* * *}$ & 0.00171 \\
\hline & $(7.93)$ & $(3.34)$ & $(1.84)$ & (14.41) & $(-0.47)$ & $(4.35)$ & $(7.56)$ & $(3.44)$ & (1.04) \\
\hline \multirow[t]{2}{*}{$\begin{array}{l}\text { Transport } \\
\text { Equipment }\end{array}$} & $0.14104^{* * *}$ & $0.15962^{\star * *}$ & 0.00018 & $0.24643^{\star * *}$ & 0.02073 & 0.00563 & $0.12413^{* * *}$ & $0.15785^{* * *}$ & -0.00020 \\
\hline & (9.58) & $(3.42)$ & $(0.15)$ & (19.58) & (0.09) & (1.29) & (9.73) & (3.43) & $(-0.18)$ \\
\hline
\end{tabular}

Note: Variables are all in first order difference form. The numbers in brackets show the $t$ value. Coefficient estimates significantly different from zero at $10 \%$, $5 \%$, and $1 \%$ level are marked ${ }^{*}, * *$ and ${ }^{* * *}$, respectively. 
Table A6. The daily regression results of the major currencies' influence on the INEER returns' jump intensity of various industries at different periods.

\begin{tabular}{|c|c|c|c|c|c|c|c|c|c|}
\hline & \multicolumn{3}{|c|}{$2001 / 1 / 1-2017 / 6 / 30$} & \multicolumn{3}{|c|}{$2001 / 1 / 1-2008 / 9 / 15$} & \multicolumn{3}{|c|}{$2008 / 9 / 16-2017 / 6 / 30$} \\
\hline & USD & DEM & JPY & USD & DEM & JPY & USD & DEM & JPY \\
\hline \multirow[t]{2}{*}{ Food } & $1.02115^{\star * *}$ & $0.98857^{\star *}$ & $0.19148^{* * *}$ & $2.38703^{\star * \star}$ & -4.10273 & $0.65511^{\star * *}$ & $0.84439^{* * *}$ & $1.23230^{* * *}$ & $0.13812^{* * *}$ \\
\hline & $(5.35)$ & $(2.26)$ & $(5.00)$ & $(10.44)$ & $(-1.64)$ & $(6.64)$ & $(4.49)$ & $(2.65)$ & $(4.42)$ \\
\hline \multirow[t]{2}{*}{ Textile } & $1.73059^{* * *}$ & $2.16370^{\star * *}$ & $0.05780^{*}$ & $3.41679^{* * *}$ & -3.03191 & $0.40059^{* * *}$ & $1.49984^{* * *}$ & $2.40232^{* * *}$ & 0.02026 \\
\hline & $(9.02)$ & $(3.88)$ & $(1.92)$ & $(15.02)$ & $(-0.97)$ & $(5.18)$ & $(9.25)$ & $(4.10)$ & $(0.84)$ \\
\hline \multirow[t]{2}{*}{ Wood } & $1.45928^{* * *}$ & $1.77090^{* * *}$ & $0.07987^{\star *}$ & $2.95725^{* * *}$ & -3.13692 & $0.43884^{* * *}$ & $1.25778^{* * *}$ & $2.00150^{* * *}$ & 0.03980 \\
\hline & $(8.71)$ & $(3.86)$ & $(2.36)$ & $(13.92)$ & $(-1.13)$ & $(5.73)$ & $(9.03)$ & $(4.17)$ & $(1.40)$ \\
\hline \multirow[t]{2}{*}{ Paper } & $0.22009^{* * *}$ & $0.15596^{\star * *}$ & $0.00896^{\star *}$ & $0.48832^{* * *}$ & -0.14174 & $0.04457^{\star * *}$ & $0.17592^{* * *}$ & $0.13949^{* * *}$ & 0.00531 \\
\hline & $(8.47)$ & $(2.92)$ & $(2.21)$ & $(13.24)$ & $(-0.75)$ & $(3.35)$ & $(8.61)$ & $(2.82)$ & $(1.57)$ \\
\hline \multirow[t]{2}{*}{ Petroleum } & $1.27176^{* * *}$ & $1.71274^{* * *}$ & $0.05448^{\star}$ & $2.84595^{\star * *}$ & 0.80731 & $0.27413^{* * *}$ & $1.00009^{* * *}$ & $1.51864^{* * *}$ & 0.03171 \\
\hline & $(8.00)$ & $(3.24)$ & (1.89) & (15.56) & $(0.24)$ & $(4.88)$ & $(7.88)$ & $(3.04)$ & $(1.23)$ \\
\hline \multirow[t]{2}{*}{ Chemical } & $-0.49705^{\star \star \star}$ & $-0.44229^{* *}$ & -0.01331 & $-1.20253^{\star * *}$ & 0.66730 & -0.03169 & $-0.38684^{\star * *}$ & $-0.45550^{* * *}$ & -0.01303 \\
\hline & $(-6.31)$ & $(-2.05)$ & $(-1.49)$ & $(-12.64)$ & $(0.36)$ & $(-0.96)$ & $(-5.80)$ & $(-2.97)$ & $(-1.53)$ \\
\hline \multirow[t]{2}{*}{ Rubber } & $2.81781^{* * *}$ & $2.95066^{\star * *}$ & 0.03302 & $5.14366^{* * *}$ & -0.39892 & $0.17700^{*}$ & $2.44855^{* * *}$ & $2.93718^{* * *}$ & 0.02175 \\
\hline & $(9.37)$ & $(3.94)$ & $(1.13)$ & (19.17) & $(-0.08)$ & (1.77) & (9.79) & $(4.23)$ & $(0.80)$ \\
\hline \multirow[t]{2}{*}{ Non-Metal } & $-0.15393^{* * *}$ & -0.09242 & -0.00461 & $-0.36863^{* * *}$ & 0.56154 & $-0.02232^{\star *}$ & $-0.12484^{* * *}$ & $-0.12879^{* * *}$ & -0.00304 \\
\hline & $(-6.97)$ & $(-1.48)$ & $(-1.56)$ & $(-10.94)$ & (1.11) & $(-2.07)$ & $(-6.61)$ & $(-2.78)$ & $(-1.17)$ \\
\hline \multirow[t]{2}{*}{ Metal } & $-0.26559^{* * *}$ & $-0.16148^{*}$ & $-0.00883^{*}$ & $-0.65648^{* * *}$ & 0.61887 & $-0.02973^{\star}$ & $-0.20679^{* * *}$ & $-0.18458^{\star *}$ & -0.00735 \\
\hline & $(-6.42)$ & $(-1.65)$ & $(-1.78)$ & $(-11.12)$ & $(0.83)$ & $(-1.68)$ & $(-5.64)$ & $(-2.26)$ & $(-1.59)$ \\
\hline \multirow[t]{2}{*}{$\begin{array}{c}\text { General } \\
\text { Machinery }\end{array}$} & $-0.19423^{\star * *}$ & $-0.16493^{\star}$ & -0.00316 & $-0.43237^{* * *}$ & 0.30907 & -0.00659 & $-0.15852^{\star * *}$ & $-0.18127^{* * *}$ & -0.00341 \\
\hline & $(-7.61)$ & $(-1.86)$ & $(-0.97)$ & $(-11.88)$ & $(0.39)$ & $(-0.49)$ & $(-7.61)$ & $(-3.35)$ & $(-1.11)$ \\
\hline \multirow{2}{*}{$\begin{array}{c}\text { Electric } \\
\text { Machinery }\end{array}$} & $2.17608^{* * *}$ & $3.25444^{\star \star *}$ & 0.03752 & $4.29114^{* * *}$ & -0.71952 & $0.22170^{* \star}$ & $1.85309^{* * *}$ & $3.33252^{* * *}$ & 0.02073 \\
\hline & $(8.65)$ & $(4.88)$ & $(1.43)$ & (16.77) & $(-0.18)$ & $(2.38)$ & $(9.03)$ & $(5.14)$ & $(0.86)$ \\
\hline \multirow[t]{2}{*}{$\begin{array}{c}\text { Optical } \\
\text { Instruments }\end{array}$} & $1.72962^{\star \star \star}$ & $1.97749^{* * *}$ & $0.06738^{\star}$ & $3.76953^{\star * *}$ & -1.67073 & $0.38471^{\star \star *}$ & $1.41332^{* * *}$ & $1.99544^{\star * \star}$ & 0.03391 \\
\hline & (7.49) & $(3.38)$ & $(1.89)$ & (14.46) & $(-0.45)$ & $(4.40)$ & $(7.44)$ & $(3.46)$ & $(1.10)$ \\
\hline \multirow[t]{2}{*}{$\begin{array}{l}\text { Transport } \\
\text { Equipment }\end{array}$} & $1.97738^{\star * \star}$ & $2.28142^{\star * *}$ & 0.00363 & $3.62522^{\star * *}$ & 0.37150 & 0.08371 & $1.70933^{* * *}$ & $2.22564^{\star \star \star}$ & -0.00165 \\
\hline & $(8.52)$ & (3.43) & $(0.21)$ & (19.79) & $(0.11)$ & (1.33) & $(8.74)$ & (3.43) & $(-0.10)$ \\
\hline
\end{tabular}

Note: Variables are all in first order difference form. The numbers in brackets show the $t$ value. Coefficient estimates significantly different from zero at $10 \%$, $5 \%$, and $1 \%$ level are marked ${ }^{*},{ }^{* *}$ and ${ }^{* * *}$, respectively. 
Table A7. The regression results of using jump variance $\left(\operatorname{var}\left[C_{t} \mid \Phi_{t-1}\right]\right)$ instead of jump intensity.

\begin{tabular}{|c|c|c|c|c|c|c|c|c|c|}
\hline & \multicolumn{3}{|c|}{$2001 / 1 / 1-2017 / 6 / 30$} & \multicolumn{3}{|c|}{$2001 / 1 / 1-2008 / 9 / 15$} & \multicolumn{3}{|c|}{ 2008/9/16-2017/6/30 } \\
\hline & USD & DEM & JPY & USD & DEM & JPY & USD & DEM & JPY \\
\hline \multirow[t]{2}{*}{ Food } & $0.08892^{* * *}$ & $0.08608^{\star *}$ & $0.01667^{\star * *}$ & $0.20785^{\star * *}$ & -0.35724 & $0.05704^{* * *}$ & $0.09136^{* * *}$ & $0.10993^{* * *}$ & $0.01488^{\star * *}$ \\
\hline & $(5.35)$ & $(2.26)$ & $(5.00)$ & $(10.44)$ & $(-1.64)$ & $(6.64)$ & $(4.49)$ & $(2.74)$ & $(4.09)$ \\
\hline \multirow[t]{2}{*}{ Textile } & $0.11084^{* * *}$ & $0.13857^{\star * *}$ & $0.00370^{\star}$ & $0.21883^{* * *}$ & -0.19418 & $0.02566^{* * *}$ & $0.09606^{* * *}$ & $0.15386^{* * *}$ & 0.00130 \\
\hline & $(9.02)$ & $(3.88)$ & $(1.92)$ & $(15.02)$ & $(-0.97)$ & $(5.18)$ & $(9.25)$ & $(4.10)$ & $(0.84)$ \\
\hline \multirow[t]{2}{*}{ Wood } & $0.11164^{* * *}$ & $0.13548^{\star * *}$ & $0.00611^{* *}$ & $0.22625^{\star * *}$ & -0.23999 & $0.03357^{* * *}$ & $0.09623^{* * *}$ & $0.15313^{* * *}$ & 0.00304 \\
\hline & $(8.71)$ & $(3.86)$ & $(2.36)$ & $(13.92)$ & $(-1.13)$ & $(5.73)$ & $(9.03)$ & $(4.17)$ & $(1.40)$ \\
\hline \multirow[t]{2}{*}{ Paper } & $0.02137^{* * *}$ & $0.01514^{\star * *}$ & $0.00087^{\star *}$ & $0.04741^{\star * *}$ & -0.01376 & $0.00433^{* * *}$ & $0.01708^{* * *}$ & $0.01354^{* * *}$ & 0.00052 \\
\hline & $(8.47)$ & $(2.92)$ & $(2.21)$ & (13.24) & $(-0.75)$ & $(3.35)$ & $(8.61)$ & $(2.82)$ & $(1.57)$ \\
\hline \multirow[t]{2}{*}{ Petroleum } & $0.09159^{* * *}$ & $0.12335^{\star * *}$ & $0.00392^{\star}$ & $0.20496^{\star * *}$ & 0.05814 & $0.01974^{* * *}$ & $0.07203^{* * *}$ & $0.10937^{* * *}$ & 0.00228 \\
\hline & $(8.00)$ & $(3.24)$ & $(1.89)$ & (15.56) & $(0.24)$ & $(4.88)$ & $(7.88)$ & $(3.04)$ & $(1.23)$ \\
\hline \multirow[t]{2}{*}{ Chemical } & $-0.02868^{\star \star \star}$ & $-0.02552^{\star *}$ & -0.00077 & $-0.06940^{* * *}$ & 0.03851 & -0.00183 & $-0.02232^{\star * *}$ & $-0.02629^{\star * *}$ & -0.00075 \\
\hline & $(-6.31)$ & $(-2.05)$ & $(-1.49)$ & $(-12.64)$ & $(0.36)$ & $(-0.96)$ & $(-5.80)$ & $(-2.97)$ & $(-1.53)$ \\
\hline \multirow[t]{2}{*}{ Rubber } & $0.07933^{* * *}$ & $0.08307^{\star * *}$ & 0.00093 & $0.14481^{\star * *}$ & -0.01123 & $0.00498^{*}$ & $0.06894^{* * *}$ & $0.08269^{* * *}$ & 0.00061 \\
\hline & $(9.37)$ & (3.94) & (1.13) & (19.17) & $(-0.08)$ & $(1.77)$ & (9.79) & $(4.23)$ & $(0.80)$ \\
\hline \multirow[t]{2}{*}{ Non-Metal } & $-0.01716^{* * *}$ & -0.01030 & -0.00051 & $-0.04110^{\star * *}$ & 0.06261 & $-0.00249^{* *}$ & $-0.01392^{\star * *}$ & $-0.01436^{* * *}$ & -0.00034 \\
\hline & $(-6.97)$ & $(-1.48)$ & $(-1.56)$ & $(-10.94)$ & $(1.11)$ & $(-2.07)$ & $(-6.61)$ & $(-2.78)$ & $(-1.17)$ \\
\hline \multirow[t]{2}{*}{ Metal } & $-0.03127^{\star * *}$ & $-0.01901^{\star}$ & $-0.00104^{*}$ & $-0.07730^{* * *}$ & 0.07287 & $-0.00350^{\star}$ & $-0.02435^{\star * *}$ & $-0.02173^{* *}$ & -0.00087 \\
\hline & $(-6.42)$ & $(-1.65)$ & $(-1.78)$ & $(-11.12)$ & $(0.83)$ & $(-1.68)$ & $(-5.64)$ & $(-2.26)$ & $(-1.59)$ \\
\hline \multirow{2}{*}{$\begin{array}{c}\text { General } \\
\text { Machinery }\end{array}$} & $-0.01617^{\star * *}$ & $-0.01373^{\star}$ & -0.00026 & $-0.03600^{* * *}$ & 0.02574 & -0.00055 & $-0.01320^{* * *}$ & $-0.01509^{* * *}$ & -0.00028 \\
\hline & $(-7.61)$ & $(-1.86)$ & $(-0.97)$ & $(-11.88)$ & $(0.39)$ & $(-0.49)$ & $(-7.61)$ & $(-3.35)$ & $(-1.11)$ \\
\hline \multirow{2}{*}{$\begin{array}{c}\text { Electric } \\
\text { Machinery }\end{array}$} & $0.09792^{* * *}$ & $0.14645^{\star \star \star}$ & 0.00169 & $0.19310^{\star * *}$ & -0.03238 & $0.00998^{\star *}$ & $0.08339^{* * *}$ & $0.14996^{* * *}$ & 0.00093 \\
\hline & $(8.65)$ & $(4.88)$ & (1.43) & (16.77) & $(-0.18)$ & $(2.38)$ & $(9.03)$ & $(5.14)$ & $(0.86)$ \\
\hline \multirow[t]{2}{*}{$\begin{array}{l}\text { Optical } \\
\text { Instruments }\end{array}$} & $0.08393^{\star * \star}$ & $0.09595^{\star \star *}$ & $0.00327^{\star}$ & $0.18291^{\star * *}$ & -0.08107 & $0.01867^{* * *}$ & $0.06858^{* * *}$ & $0.09682^{* * *}$ & 0.00165 \\
\hline & $(7.49)$ & $(3.38)$ & (1.89) & (14.46) & $(-0.45)$ & $(4.40)$ & $(7.44)$ & $(3.46)$ & $(1.10)$ \\
\hline \multirow{2}{*}{$\begin{array}{l}\text { Transport } \\
\text { Equipment }\end{array}$} & $0.12431^{\star \star \star}$ & $0.14343^{\star * \star}$ & 0.00023 & $0.22791^{\star \star \star}$ & 0.02336 & 0.00526 & $0.10746^{* * *}$ & $0.13992^{* * *}$ & -0.00010 \\
\hline & $(8.52)$ & (3.43) & $(0.21)$ & (19.79) & $(0.11)$ & (1.33) & $(8.74)$ & (3.43) & $(-0.10)$ \\
\hline
\end{tabular}

Note: Variables are all in first order difference form. The numbers in brackets show the $t$ value. Coefficient estimates significantly different from zero at $10 \%$, $5 \%$, and $1 \%$ level are marked ${ }^{*}, * *$ and ${ }^{* *}$, respectively. 
Table A8. The regression results of using jump intensity estimated by ARJI- $h_{t}$ model instead of basic ARJI model.

\begin{tabular}{|c|c|c|c|c|c|c|c|c|c|}
\hline & \multicolumn{3}{|c|}{$2001 / 1 / 1-2017 / 6 / 30$} & \multicolumn{3}{|c|}{$2001 / 1 / 1-2008 / 9 / 15$} & \multicolumn{3}{|c|}{$2008 / 9 / 16-2017 / 6 / 30$} \\
\hline & USD & DEM & JPY & USD & DEM & JPY & USD & DEM & JPY \\
\hline \multirow[t]{2}{*}{ Food } & $0.01272^{* * *}$ & $0.00792^{*}$ & $0.00167^{\star * *}$ & $0.02486^{* * *}$ & $-0.05184^{\star *}$ & $0.00658^{* * *}$ & $0.01135^{\star *}$ & $0.01152^{\star *}$ & $0.00110^{* * *}$ \\
\hline & $(3.14)$ & $(1.66)$ & $(4.04)$ & $(9.25)$ & $(-1.98)$ & $(5.73)$ & $(2.30)$ & $(2.32)$ & $(2.93)$ \\
\hline \multirow{2}{*}{ Textile } & $0.04659^{* * *}$ & $0.03822^{* * *}$ & 0.00081 & $0.06093^{* * *}$ & -0.07874 & $0.00733^{* * *}$ & $0.04564^{* * *}$ & $0.04749^{* * *}$ & 0.00005 \\
\hline & $(4.68)$ & $(3.05)$ & $(1.16)$ & $(12.25)$ & $(-1.35)$ & $(4.08)$ & $(3.88)$ & $(3.62)$ & $(0.08)$ \\
\hline \multirow[t]{2}{*}{ Wood } & $0.01310^{* * *}$ & $0.01029^{* * *}$ & $0.00050^{*}$ & $0.02169^{* * *}$ & -0.03115 & $0.00319^{* * *}$ & $0.01213^{* * *}$ & $0.01295^{\star * *}$ & 0.00019 \\
\hline & $(4.90)$ & $(2.89)$ & $(1.93)$ & $(11.71)$ & $(-1.50)$ & $(4.30)$ & $(3.74)$ & $(3.52)$ & $(0.87)$ \\
\hline \multirow[t]{2}{*}{ Paper } & $0.09009^{* * *}$ & 0.02392 & $0.00183^{\star}$ & $0.11597^{\star * *}$ & -0.15173 & $0.00925^{\star * *}$ & $0.08793^{* * *}$ & $0.03780^{* * *}$ & 0.00099 \\
\hline & $(7.01)$ & $(1.53)$ & $(1.80)$ & $(13.74)$ & $(-1.58)$ & $(2.82)$ & $(5.82)$ & $(2.70)$ & $(1.09)$ \\
\hline \multirow[t]{2}{*}{ Petroleum } & $0.03008^{* * *}$ & $0.03842^{\star * *}$ & 0.00060 & $0.04370^{* * *}$ & -0.00088 & $0.00398^{* * *}$ & $0.02817^{* * *}$ & $0.03989^{* * *}$ & 0.00022 \\
\hline & $(3.95)$ & $(2.70)$ & $(1.10)$ & $(13.12)$ & $(-0.02)$ & $(4.15)$ & $(3.07)$ & $(2.65)$ & $(0.41)$ \\
\hline \multirow[t]{2}{*}{ Chemical } & $0.07886^{* * *}$ & $0.04185^{\star *}$ & 0.00117 & $0.10309^{* * *}$ & -0.04527 & $0.00423^{*}$ & $0.07576^{\star * *}$ & $0.04718^{\star *}$ & 0.00086 \\
\hline & $(5.60)$ & $(2.04)$ & (1.29) & $(14.22)$ & $(-0.42)$ & (1.79) & $(4.56)$ & $(2.41)$ & $(0.94)$ \\
\hline \multirow[t]{2}{*}{ Rubber } & $0.01513^{* * *}$ & $0.00978^{\star * *}$ & 0.00010 & $0.01647^{* * *}$ & -0.01001 & 0.00074 & $0.01517^{* * *}$ & $0.01164^{* * *}$ & 0.00002 \\
\hline & (5.93) & $(2.72)$ & $(0.65)$ & (13.85) & $(-0.50)$ & $(1.30)$ & $(5.14)$ & $(3.54)$ & $(0.16)$ \\
\hline \multirow[t]{2}{*}{ Non-Metal } & $0.12238^{* * *}$ & $0.04734^{*}$ & 0.00149 & $0.13826^{* * *}$ & -0.13838 & $0.00993^{\star * *}$ & $0.12213^{* * *}$ & $0.06360^{* * *}$ & 0.00050 \\
\hline & $(7.02)$ & (1.90) & $(1.20)$ & $(13.52)$ & $(-1.09)$ & $(2.65)$ & $(6.04)$ & $(2.71)$ & $(0.43)$ \\
\hline \multirow{2}{*}{$\begin{array}{c}\text { General } \\
\text { Machinery }\end{array}$} & $0.08199^{* * *}$ & $0.05880^{\star * *}$ & 0.00038 & $0.08877^{* * *}$ & -0.00464 & 0.00282 & $0.08168^{\star * *}$ & $0.06427^{* * *}$ & 0.00010 \\
\hline & $(5.77)$ & $(2.91)$ & $(0.51)$ & (14.45) & $(-0.05)$ & $(1.24)$ & $(4.93)$ & $(3.35)$ & $(0.14)$ \\
\hline \multirow[t]{2}{*}{$\begin{array}{c}\text { Electric } \\
\text { Machinery }\end{array}$} & $0.01740^{\star \star \star *}$ & $0.01664^{\star * *}$ & 0.00017 & $0.02167^{* * *}$ & -0.01885 & $0.00130^{* *}$ & $0.01714^{\star * *}$ & $0.01969^{* * *}$ & 0.00004 \\
\hline & $(6.03)$ & $(3.17)$ & $(0.94)$ & (12.49) & $(-0.70)$ & $(2.02)$ & $(5.12)$ & (3.85) & $(0.25)$ \\
\hline \multirow[t]{2}{*}{$\begin{array}{c}\text { Optical } \\
\text { Instruments }\end{array}$} & $0.01754^{\star \star \star}$ & $0.01401^{\star *}$ & 0.00040 & $0.02800^{* * *}$ & -0.02871 & $0.00283^{* * *}$ & $0.01626^{\star * *}$ & $0.01660^{* * *}$ & 0.00013 \\
\hline & $(4.94)$ & $(2.32)$ & $(1.29)$ & (12.28) & $(-0.89)$ & $(3.44)$ & (3.85) & $(2.74)$ & $(0.45)$ \\
\hline \multirow{2}{*}{$\begin{array}{l}\text { Transport } \\
\text { Equipment }\end{array}$} & $0.02047^{* * *}$ & $0.01914^{* * *}$ & -0.00006 & $0.02279^{* * *}$ & -0.00743 & 0.00047 & $0.02044^{\star * *}$ & $0.02164^{* * *}$ & -0.00012 \\
\hline & (6.48) & $(2.80)$ & $(-0.35)$ & (13.69) & $(-0.28)$ & $(0.86)$ & (5.62) & (3.08) & $(-0.70)$ \\
\hline
\end{tabular}

Note: Variables are all in first order difference form. The numbers in brackets show the $t$ value. Coefficient estimates significantly different from zero at $10 \%$, $5 \%$, and $1 \%$ level are marked ${ }^{*}, * *$ and ${ }^{* *}$, respectively. 
Table A9. The monthly regression results of the major currencies' influence on the INEER returns' volatility of various industries at different periods.

\begin{tabular}{|c|c|c|c|c|c|c|c|c|c|}
\hline & \multicolumn{3}{|c|}{ 2001-01-2017-06 } & \multicolumn{3}{|c|}{$2001-01-2008-08$} & \multicolumn{3}{|c|}{ 2008-09-2017-06 } \\
\hline & USD & DEM & JPY & USD & DEM & JPY & USD & DEM & JPY \\
\hline \multirow[t]{2}{*}{ Food } & $0.09428^{* *}$ & 0.20629 & $0.01176^{*}$ & $0.23127^{\star * *}$ & 0.01547 & $0.08298^{\star * *}$ & $0.08339^{* *}$ & 0.18313 & 0.00730 \\
\hline & $(2.44)$ & (1.53) & (1.90) & $(3.71)$ & $(0.05)$ & $(6.37)$ & $(2.11)$ & $(1.36)$ & $(1.51)$ \\
\hline \multirow[t]{2}{*}{ Textile } & $0.10199^{* * *}$ & $0.31213^{* * *}$ & 0.00180 & $0.22763^{* * *}$ & 0.10047 & $0.03428^{* * *}$ & $0.08893^{* *}$ & $0.30125^{\star * *}$ & 0.00052 \\
\hline & (2.99) & $(2.83)$ & $(0.39)$ & $(5.46)$ & $(0.42)$ & $(4.27)$ & $(2.50)$ & $(2.76)$ & $(0.12)$ \\
\hline \multirow[t]{2}{*}{ Wood } & $0.10737^{\star * *}$ & 0.19824 & 0.00194 & $0.25931^{\star * \star}$ & 0.07726 & $0.05024^{\star * *}$ & $0.09073^{\star *}$ & 0.17453 & -0.00024 \\
\hline & $(3.10)$ & $(1.54)$ & $(0.38)$ & $(5.67)$ & $(0.34)$ & $(5.16)$ & $(2.60)$ & (1.37) & $(-0.06)$ \\
\hline \multirow[t]{2}{*}{ Paper } & $0.10246^{* * *}$ & 0.11157 & 0.00411 & $0.16343^{\star * *}$ & 0.07018 & 0.01250 & $0.09449^{\star * *}$ & 0.10434 & $0.00420^{*}$ \\
\hline & $(5.51)$ & $(1.64)$ & $(1.62)$ & $(5.25)$ & $(0.38)$ & (1.35) & $(5.02)$ & $(1.52)$ & (1.67) \\
\hline \multirow[t]{2}{*}{ Petroleum } & $0.09653^{* *}$ & $0.32291^{\star *}$ & -0.00383 & $0.27418^{* * *}$ & 0.52793 & $0.03635^{* * *}$ & 0.07032 & $0.27837^{\star}$ & -0.00454 \\
\hline & $(2.07)$ & $(2.04)$ & $(-0.68)$ & $(5.82)$ & $(1.57)$ & $(3.71)$ & $(1.46)$ & $(1.80)$ & $(-0.91)$ \\
\hline \multirow[t]{2}{*}{ Chemical } & $0.18104^{* * *}$ & 0.17706 & 0.00621 & $0.29377^{\star * *}$ & 0.15224 & 0.00775 & $0.16403^{\star * *}$ & 0.16403 & $0.00765^{\star}$ \\
\hline & (5.78) & $(1.61)$ & (1.39) & $(8.10)$ & $(0.71)$ & $(1.39)$ & $(5.00)$ & $(1.51)$ & $(1.71)$ \\
\hline \multirow[t]{2}{*}{ Rubber } & $0.08088^{* * *}$ & $0.16165^{\star \star}$ & 0.00033 & $0.16200^{\star * *}$ & 0.04628 & $0.00814^{\star \star}$ & $0.07071^{\star * *}$ & $0.15660^{* \star}$ & 0.00068 \\
\hline & $(3.91)$ & $(2.54)$ & $(0.13)$ & $(6.77)$ & $(0.31)$ & $(2.61)$ & $(3.40)$ & $(2.51)$ & $(0.26)$ \\
\hline \multirow[t]{2}{*}{ Non-Metal } & $0.18952^{* * *}$ & 0.16537 & $0.01021^{\star *}$ & $0.23961^{\star * *}$ & 0.00895 & $0.01826^{\star *}$ & $0.18478^{\star * *}$ & 0.16666 & $0.01005^{*}$ \\
\hline & $(6.01)$ & $(1.52)$ & $(2.01)$ & $(6.80)$ & $(0.04)$ & $(2.21)$ & $(5.24)$ & (1.49) & (1.76) \\
\hline \multirow[t]{2}{*}{ Metal } & $0.24509^{* * *}$ & 0.09321 & $0.02299^{\star *}$ & $0.26605^{\star * *}$ & 0.10616 & 0.01132 & $0.24035^{* * *}$ & 0.09272 & $0.02432^{* *}$ \\
\hline & $(6.44)$ & $(0.76)$ & $(2.36)$ & (7.09) & $(0.44)$ & $(1.25)$ & $(5.50)$ & $(0.74)$ & $(2.28)$ \\
\hline \multirow[t]{2}{*}{$\begin{array}{c}\text { General } \\
\text { Machinery }\end{array}$} & $0.12008^{\star * *}$ & $0.24403^{* *}$ & 0.00088 & $0.20838^{* * *}$ & 0.18470 & $0.00716^{* *}$ & $0.10784^{\star * *}$ & $0.23503^{\star *}$ & 0.00152 \\
\hline & $(4.16)$ & $(2.52)$ & $(0.28)$ & (8.49) & $(1.02)$ & $(2.36)$ & $(3.60)$ & $(2.42)$ & $(0.48)$ \\
\hline \multirow{2}{*}{$\begin{array}{c}\text { Electric } \\
\text { Machinery }\end{array}$} & $0.11808^{\star * *}$ & $0.24601^{\star *}$ & 0.00113 & $0.23743^{* * *}$ & 0.18253 & $0.01337^{* *}$ & $0.10172^{\star * *}$ & $0.23191^{\star *}$ & 0.00169 \\
\hline & $(4.20)$ & $(2.58)$ & $(0.33)$ & $(7.08)$ & $(0.82)$ & $(2.17)$ & $(3.64)$ & $(2.49)$ & $(0.50)$ \\
\hline \multirow[t]{2}{*}{$\begin{array}{c}\text { Optical } \\
\text { Instruments }\end{array}$} & $0.09842^{* * *}$ & $0.19145^{\star}$ & 0.00055 & $0.20892^{\star * *}$ & 0.18655 & $0.02629^{* * *}$ & $0.08410^{* * *}$ & 0.17154 & -0.00012 \\
\hline & $(3.22)$ & $(1.82)$ & $(0.14)$ & (5.59) & $(0.91)$ & $(3.91)$ & $(2.65)$ & $(1.65)$ & $(-0.03)$ \\
\hline \multirow{2}{*}{$\begin{array}{l}\text { Transport } \\
\text { Equipment }\end{array}$} & $0.14211^{* * *}$ & $0.35383^{* * *}$ & -0.00203 & $0.28784^{\star \star \star}$ & 0.31393 & 0.00800 & $0.12107^{\star \star *}$ & $0.33554^{* * *}$ & -0.00087 \\
\hline & $(3.73)$ & $(3.06)$ & $(-0.41)$ & $(8.02)$ & $(1.22)$ & $(1.61)$ & $(3.12)$ & $(2.98)$ & $(-0.18)$ \\
\hline
\end{tabular}

Note: Variables are all in first order difference form. The numbers in brackets show the $t$ value. Coefficient estimates significantly different from zero at $10 \%$, $5 \%$, and $1 \%$ level are marked ${ }^{*}, * *$ and ${ }^{* * *}$, respectively. 
Table A10. The monthly regression results of the major currencies' influence on the INEER returns' jump intensity of various industries at different periods.

\begin{tabular}{|c|c|c|c|c|c|c|c|c|c|}
\hline & \multicolumn{3}{|c|}{$2001-01-2017-06$} & \multicolumn{3}{|c|}{ 2001-01-2008-08 } & \multicolumn{3}{|c|}{ 2008-09-2017-06 } \\
\hline & USD & DEM & JPY & USD & DEM & JPY & USD & DEM & JPY \\
\hline \multirow[t]{2}{*}{ Food } & $20.63999^{* *}$ & $51.07500^{*}$ & 2.22187 & $50.38435^{* * *}$ & 2.93963 & $19.18061^{\star * *}$ & $18.51407^{\star}$ & 46.11905 & 1.11838 \\
\hline & $(2.17)$ & $(1.81)$ & $(1.55)$ & $(3.60)$ & $(0.04)$ & $(6.93)$ & $(1.97)$ & $(1.63)$ & $(0.96)$ \\
\hline \multirow[t]{2}{*}{ Textile } & $31.58642^{* * *}$ & $97.97321^{\star * *}$ & -0.04078 & $70.26721^{* * *}$ & 18.00094 & $11.00614^{\star * *}$ & $27.86349^{* * *}$ & $95.31032^{\star * *}$ & -0.53944 \\
\hline & $(2.94)$ & $(3.34)$ & $(-0.03)$ & $(5.39)$ & $(0.24)$ & $(4.46)$ & $(2.63)$ & $(3.28)$ & $(-0.46)$ \\
\hline \multirow[t]{2}{*}{ Wood } & $28.26083^{* * *}$ & $53.36354^{\star}$ & 0.01482 & $66.53077^{\star * \star}$ & 15.89467 & $13.12977^{* * *}$ & $24.25006^{* * *}$ & 47.62177 & -0.62224 \\
\hline & $(3.08)$ & $(1.72)$ & $(0.01)$ & $(5.83)$ & $(0.26)$ & $(5.61)$ & $(2.80)$ & $(1.54)$ & $(-0.60)$ \\
\hline \multirow[t]{2}{*}{ Paper } & 0.04771 & 0.97661 & -0.00644 & 0.92855 & -0.24497 & 0.11096 & -0.05985 & 0.91223 & -0.00547 \\
\hline & $(0.06)$ & $(0.57)$ & $(-0.05)$ & $(0.73)$ & $(-0.03)$ & $(0.46)$ & $(-0.07)$ & $(0.50)$ & $(-0.04)$ \\
\hline \multirow[t]{2}{*}{ Petroleum } & $24.82687^{* *}$ & $74.21588^{* *}$ & -1.40469 & $69.90480^{* * *}$ & 108.1245 & $10.11494^{* * *}$ & $18.56646^{*}$ & $63.70660^{* *}$ & -1.72007 \\
\hline & $(2.27)$ & $(2.26)$ & $(-1.02)$ & $(5.54)$ & $(1.40)$ & $(4.16)$ & (1.79) & $(2.00)$ & $(-1.41)$ \\
\hline \multirow[t]{2}{*}{ Chemical } & 0.01349 & 2.01854 & $-0.37936^{*}$ & -1.74891 & -1.94275 & -0.09374 & 0.37273 & 2.41275 & $-0.43368^{\star}$ \\
\hline & $(0.02)$ & $(0.53)$ & $(-1.71)$ & $(-0.49)$ & $(-0.09)$ & $(-0.12)$ & $(0.41)$ & $(0.62)$ & $(-1.89)$ \\
\hline \multirow[t]{2}{*}{ Rubber } & $61.47823^{* * *}$ & $128.4837^{* * *}$ & -1.23037 & $123.7907^{* * *}$ & 18.74388 & $6.15363^{* *}$ & $54.07620^{* * *}$ & $1.3 \mathrm{e}+02^{* * *}$ & -1.10623 \\
\hline & (3.33) & $(2.90)$ & $(-0.65)$ & $(6.86)$ & $(0.18)$ & $(2.10)$ & $(2.95)$ & $(2.85)$ & $(-0.52)$ \\
\hline \multirow[t]{2}{*}{ Non-Metal } & -0.06463 & 1.13134 & $-0.13612^{*}$ & -1.01662 & 0.70837 & -0.11284 & 0.09115 & 1.27215 & $-0.15208^{*}$ \\
\hline & $(-0.20)$ & $(0.84)$ & $(-1.70)$ & $(-0.75)$ & $(0.08)$ & $(-0.37)$ & $(0.26)$ & $(0.94)$ & $(-1.86)$ \\
\hline \multirow[t]{2}{*}{ Metal } & 0.12100 & 0.58018 & $\begin{array}{c}-0.17490^{*} \\
\star\end{array}$ & -1.00465 & -0.87817 & -0.18687 & 0.31486 & 0.81367 & $-0.19154^{\star \star}$ \\
\hline & $(0.42)$ & $(0.51)$ & $(-2.51)$ & $(-0.86)$ & $(-0.12)$ & $(-0.69)$ & (1.13) & $(0.72)$ & $(-2.61)$ \\
\hline \multirow[t]{2}{*}{$\begin{array}{c}\text { General } \\
\text { Machinery }\end{array}$} & -0.13366 & 1.34823 & -0.16022 & -1.10609 & 0.73212 & -0.08165 & 0.03449 & 1.48881 & -0.18157 \\
\hline & $(-0.27)$ & $(0.74)$ & $(-1.40)$ & $(-0.61)$ & $(0.07)$ & $(-0.20)$ & $(0.06)$ & $(0.80)$ & $(-1.54)$ \\
\hline \multirow[t]{2}{*}{$\begin{array}{c}\text { Electric } \\
\text { Machinery }\end{array}$} & $51.12407^{* * *}$ & $107.7566^{\star * *}$ & -0.31982 & $106.7165^{* * *}$ & 62.73769 & $6.12758^{* *}$ & $43.78075^{* * *}$ & $1.0 \mathrm{e}+02^{* * *}$ & -0.13731 \\
\hline & $(3.56)$ & $(3.08)$ & $(-0.23)$ & $(7.63)$ & $(0.69)$ & $(2.09)$ & $(3.21)$ & $(2.98)$ & $(-0.09)$ \\
\hline \multirow[t]{2}{*}{$\begin{array}{c}\text { Optical } \\
\text { Instruments }\end{array}$} & $40.08603^{\star * *}$ & $80.32524^{\star \star}$ & -0.45085 & $86.32887^{* * *}$ & 54.92876 & $11.34007^{* * *}$ & $34.50709^{* * *}$ & $73.20438^{*}$ & -0.84309 \\
\hline & $(3.14)$ & $(2.10)$ & $(-0.32)$ & $(5.56)$ & $(0.64)$ & (3.96) & $(2.79)$ & (1.93) & $(-0.63)$ \\
\hline \multirow[t]{2}{*}{$\begin{array}{l}\text { Transport } \\
\text { Equipment }\end{array}$} & $44.02210^{\star * *}$ & $109.0132^{* * *}$ & -1.32205 & $92.31994^{* * *}$ & 84.07894 & 2.76461 & $37.27929^{* * *}$ & $1.0 \mathrm{e}+02^{\star \star *}$ & -1.01533 \\
\hline & (3.39) & $(3.67)$ & $(-1.08)$ & $(8.28)$ & (1.13) & $(1.42)$ & (2.98) & $(3.60)$ & $(-0.77)$ \\
\hline
\end{tabular}

Note: Variables are all in first order difference form. The numbers in brackets show the t value. Coefficient estimates significantly different from zero at $10 \%$, $5 \%$, and $1 \%$ level are marked ${ }^{*}, * *$ and ${ }^{* *}$, respectively. 


\section{Appendix B}

In this paper, I use the WinRATS Pro 8.0 software to estimate the cumulant likelihood of the ARJI model. Take the Food Industry as an example, the code of WinRATS Pro 8.0 software is as follows:

file for Food before 2017, using the program of Chan \& Maheu (2002), Conditional Jump Dynamics in Stock

${ }^{*}$ ARJI model (Table A3)

source jumpgarch.src

OPEN DATA “F:\MYDATA \INEER\dlind1.prn”

DATA(FORMAT $=$ PRN, NOLABELS, ORG = COLUMNS) 117201 YEAR MONTH DAY LOGRET

set $r=100.0^{\star}$ LOGRET

*

sstats $(\max ) / \% \operatorname{if}($ year $(\mathrm{t}) \leq 2017, \mathrm{t}, 0)>>$ x2017

compute end $2017=\operatorname{fix}(\mathrm{x} 2017)$

set $\mathrm{u}=0.0$

set $\mathrm{h}=0.0$

${ }^{*}$ I need these series to form the recursive estimates of the jump intensity

set lam $=0.0$

set $\mathrm{xi}=0.0$

${ }^{\star}$ Define formula for the mean model and set up its parameter set

nonlin(parmset $=$ meanparms) $\mathrm{mu}$ al a2

frml uf $=\mathrm{r}-\mathrm{mu}-\mathrm{a} 1^{\star} \mathrm{r}\{1\}-\mathrm{a} 2^{\star} \mathrm{r}\{2\}$

* Define formula for the base GARCH variance and set up its parameter set

nonlin(parmset $=$ garchparms) omega alpha beta

frml hf $=$ omega + alpha $^{\star} u\{1\}^{\wedge} 2+$ beta $^{\star} h\{1\}$

${ }^{\star}$ Define the ARJI formula for the intensity.

declare real lambda0 rho gamma

frml lambdaf $=$ lambda0 $+\operatorname{rho}^{*} \operatorname{lam}\{1\}+$ gamma $^{\star} x i\{1\}$

$* * * * * * * * * * * * * * * * * * * * * * * * * * * * * * * * * * * * * * * * * * * * * * * * * * * * * * * * * * * * * * * * * * * * * * * * * * * * * * * * * * * * * * * *)$

* The parmsets and logl definitions need to change from model to model 


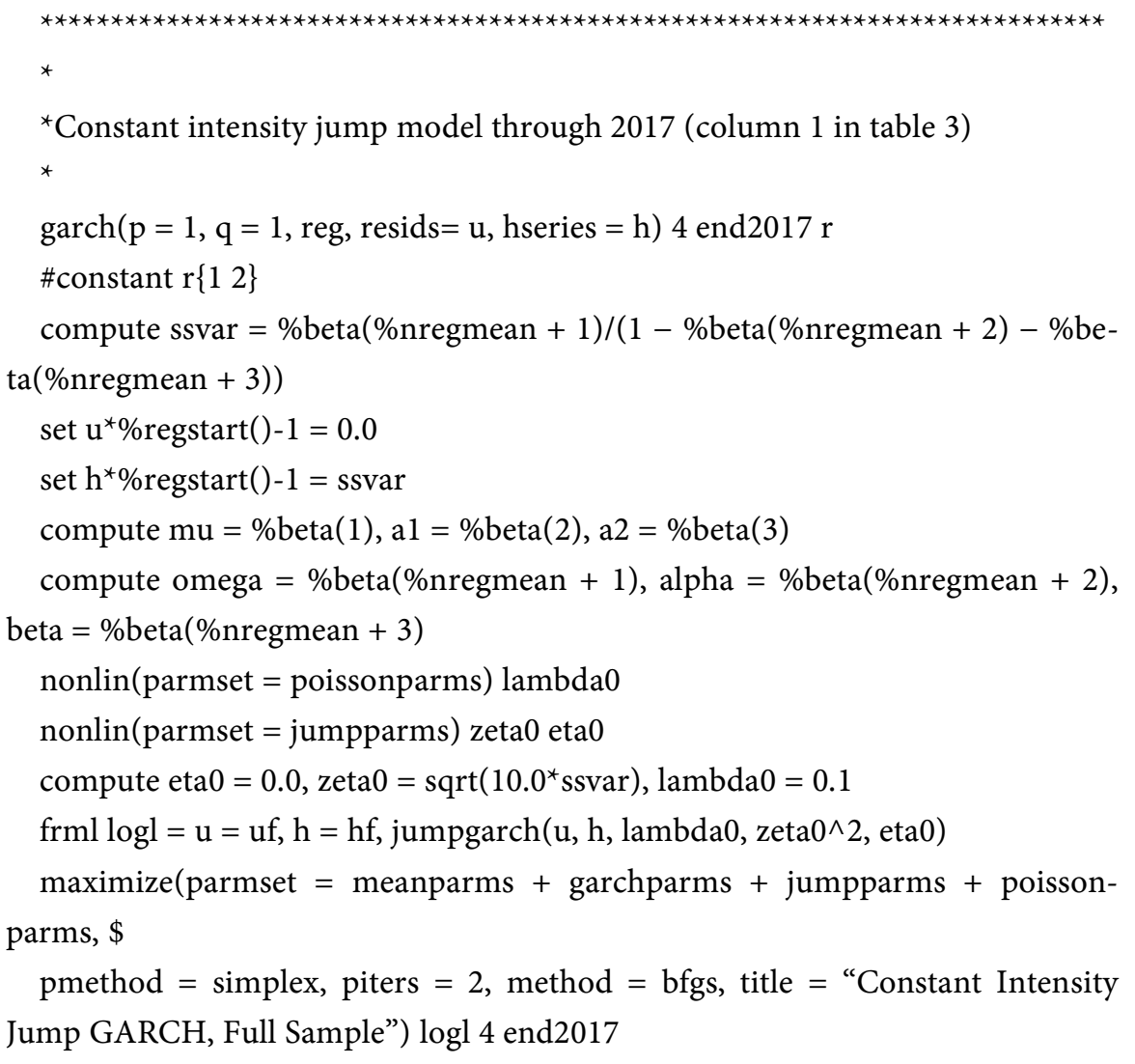

* Simple ARJI model (estimate results of parameters are in Table A3). I'll just take the

${ }^{*}$ converged estimates from the constant model as the initial guesses.

*

nonlin (parmset $=$ poissonparms) lambda0 rho gamma

compute lambda $0=0.05$, rho $=0.5$, gamma $=0.05$

frml $\log \mathrm{l}=\mathrm{u}=\mathrm{uf}, \mathrm{h}=\mathrm{hf}, \mathrm{lam}=$ lambdaf, $\operatorname{ARJIgarch}\left(\mathrm{u}, \mathrm{h}, \operatorname{lam}, \mathrm{zeta} 0^{\wedge} 2\right.$, eta 0, $\mathrm{xi})$

maximize $($ parmset $=$ meanparms + garchparms + jumpparms + poissonparms, \$

pmethod $=$ simplex, piters $=2$, method $=$ bfgs, title $=$ "ARJI-GARCH") $\operatorname{logl} 4$ end 2017

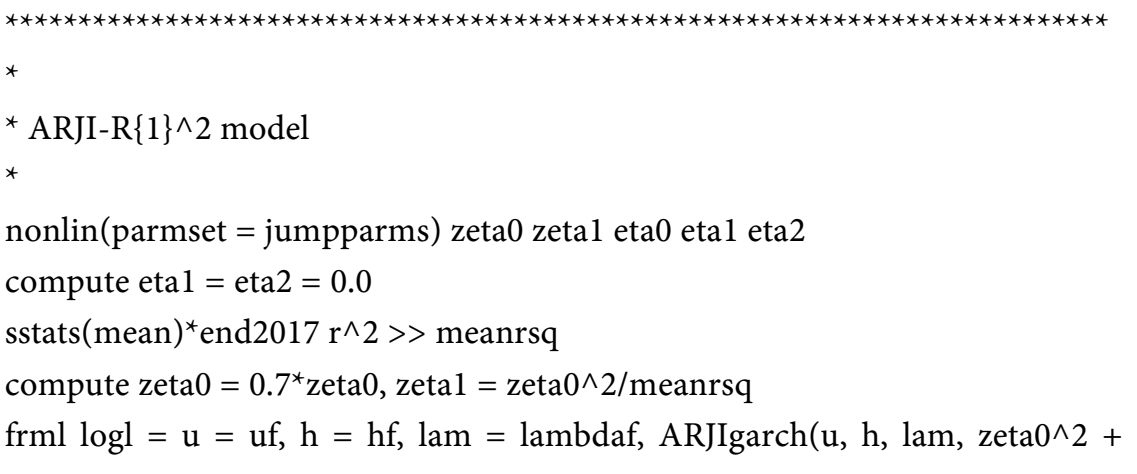




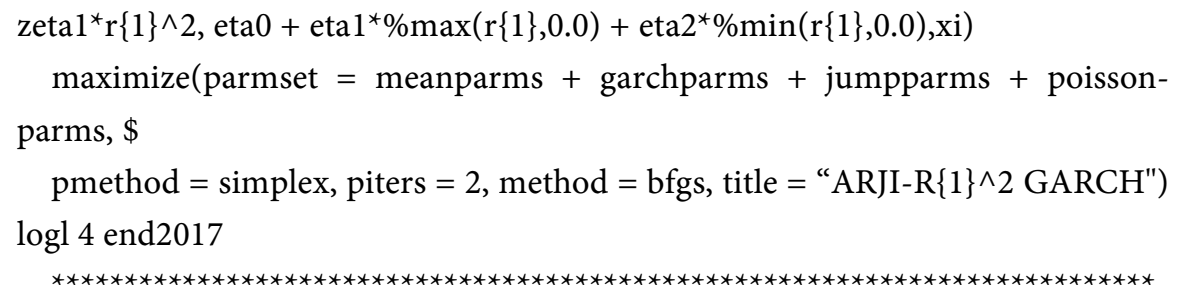

${ }^{\star} \mathrm{ARJI}-\mathrm{h}(\mathrm{t})$ model

*

nonlin(parmset $=$ jumpparms) zeta0 zeta 1 eta 0 eta 1 eta2

frml $\log \mathrm{l}=\mathrm{u}=\mathrm{uf}, \mathrm{h}=\mathrm{hf}$, lam = lambdaf, $\operatorname{ARJIgarch}\left(\mathrm{u}, \mathrm{h}, \operatorname{lam}, \mathrm{zeta} 0^{\wedge} 2+\right.$ zeta $1^{\star} h$, eta $0+$ eta $1^{\star} \% \max (r\{1\}, 0.0)+$ eta $\left.2^{\star} \% \min (r\{1\}, 0.0), x i\right)$

maximize $($ parmset $=$ meanparms + garchparms + jumpparms + poissonparms, \$

pmethod $=$ simplex, piters $=2$, method $=$ bfgs, title $=$ "ARJI-h GARCH") logl 4 end 2017 